\title{
Indirect Medium Spiny Neurons in the Dorsomedial Striatum Regulate Ethanol-Containing Conditioned Reward Seeking
}

\author{
[DSa-Ik Hong, ${ }^{1 *}{ }^{\mathbb{C} S}$ Seungwoo Kang, ${ }^{1 *}$ Jiang-Fan Chen, ${ }^{4}$ and ${ }^{-D o o-S u p ~ C h o i ~}{ }^{1,2,3}$ \\ Departments of ${ }^{1}$ Molecular Pharmacology and Experimental Therapeutics, ${ }^{2}$ Psychiatry and Psychology, ${ }^{3}$ Neuroscience Program, Mayo Clinic College of \\ Medicine, Rochester, Minnesota 55905, and ${ }^{4}$ Department of Neurology, Boston University School of Medicine, Boston, Massachusetts 02118
}

Adenosine $2 \mathrm{~A}$ receptor $\left(\mathrm{A}_{2 \mathrm{~A}} \mathrm{R}\right)$-containing indirect medium spiny neurons (iMSNs) in the dorsomedial striatum (DMS) contribute to reward-seeking behaviors. However, those roles for ethanol-seeking behaviors remain unknown. To investigate ethanol-seeking behaviors, we used an ethanol-containing reward (10\% ethanol and 10\% sucrose solution; 10E10S). Upon conditioning with 10E10S, mice that initially only preferred $10 \%$ sucrose, not $10 \mathrm{E} 10 \mathrm{~S}$, showed a stronger preference for $10 \mathrm{E} 10 \mathrm{~S}$. Then, we investigated whether the manipulation of the DMS- external globus pallidus (GPe) iMSNs circuit alters the ethanol-containing reward (10E10S) seeking behaviors using the combination of pharmacologic and optogenetic approaches. DMS $\mathrm{A}_{2 \mathrm{~A}} \mathrm{R}$ activation dampened operant conditioning-induced ethanolcontaining reward, whereas $A_{2 A} R$ antagonist abolished the effects of the $A_{2 A} R$ agonist and restored ethanol-containing reward-seeking. Moreover, pre-ethanol exposure potentiated the $\mathrm{A}_{2 \mathrm{~A}} \mathrm{R}$-dependent reward-seeking. Interestingly, mice exhibiting ethanol-containing reward-seeking showed the reduction of the DMS iMSNs activity, suggesting that disinhibiting iMSNs decreases reward-seeking behaviors. In addition, we found that $\mathrm{A}_{2 \mathrm{~A}} \mathrm{R}$ activation reversed iMSNs neural activity in the DMS. Similarly, optogenetic stimulation of the DMS-GPe iMSNs reduced ethanol-containing reward-seeking, whereas optogenetic inhibition of the DMS-GPe iMSNs reversed this change. Together, our study demonstrates that DMS $\mathrm{A}_{2 \mathrm{~A}} \mathrm{R}$ and iMSNs regulate ethanol-containing reward-seeking behaviors.

Key words: $\mathrm{A}_{2 \mathrm{~A}} \mathrm{R}$; dorsomedial striatum; ethanol; medium spiny neuron; reward

Significance Statement

Our findings highlight the mechanisms of how operant conditioning develops the preference of ethanol-containing conditioned reward. Mice exhibiting ethanol-containing reward-seeking showed a reduction of the indirect medium spiny neuronal activity in the dorsomedial striatum. Pharmacological activation of adenosine $A_{2 A}$ receptor $\left(A_{2 A} R\right)$ or optogenetic activation of indirect medium spiny neurons dampened operant conditioned ethanol-containing reward-seeking, whereas inhibiting this neuronal activity restored ethanol-containing reward-seeking. Furthermore, repeated intermittent ethanol exposure potentiated $\mathrm{A}_{2 \mathrm{~A}} \mathrm{R}$ dependent reward-seeking. Therefore, our finding suggests that $\mathrm{A}_{2 \mathrm{~A}} \mathrm{R}$-containing indirect medium spiny neuronal activation reduces ethanol-containing reward-seeking, which may provide a potential therapeutic target for alcohol use disorder.

\section{Introduction}

For the volitional decision-making process, two distinct networks regulate reward-seeking behaviors based on the value of goals: the sensorimotor network (stimulus-response association)

Received April 17, 2019; revised July 1, 2019; accepted July 3, 2019.

Author contributions:S.-I.H.,S.K., and D.-S.C. designed research;S.-I.H. and S.K. performed research;S.-I.H., S.K., and D.-S.C. analyzed data; S.-I.H., S.K., J.-F.C., and D.-S.C. wrote the paper.

This work was supported by the Samuel C. Johnson for Genomics of Addiction Program at Mayo Clinic, the UIm Foundation, the Godby Foundation, David Lehr Research Award from American Society for Pharmacology and Experimental Therapeutics, and National Institute on Alcohol Abuse and Alcoholism (AA018779). We thank DeAnn Frederixon and Amanda Grebinoski for proofreading the paper and helpful comments, and Dr. Karl Deisseroth at Stanford University for providing viruses for optogenetics.

*S.-I.H. and S.K. contributed equally to this work. and associative network (action-outcome association; Yin and Knowlton, 2006; Jahanshahi et al., 2015; Lovinger and Alvarez, 2017). In the associative network, the dorsomedial striatum (DMS; caudate) receiving massive projections from cortex and thalamus regulates the anticipation of reward and delayed alternation performances (Yin and Knowlton, 2006).

D.-S.C. is a scientific advisory board member to Peptron Inc., and Peptron had no role in the preparation, review, or approval of the paper; nor the decision to submit the paper for publication. The remaining authors declare no competing financial interests.

Correspondence should be addressed to Doo-Sup Choi at choids@mayo.edu.

https://doi.org/10.1523/JNEUROSCI.0876-19.2019

Copyright $\odot 2019$ the authors 
Most dorsal striatal neurons are gamma-aminobutyric acidergic (GABAergic) inhibitory medium spiny neurons (MSNs), which are mainly composed of either dopamine $D_{1}$ receptor $\left(D_{1} R\right)$-expressing direct pathway [direct medium spiny neurons (dMSNs)] or dopamine $\mathrm{D}_{2}$ receptor/adenosine $\mathrm{A}_{2 \mathrm{~A}}$ receptorexpressing indirect pathway [indirect medium spiny neurons (iMSNs); Ferré et al., 1997; Wang et al., 2015]. $\mathrm{A}_{2 \mathrm{~A}} \mathrm{R}$, which is predominantly expressed in the striatum unlike $A_{1} R$ widely expressed in the brain, contributes to neurodegenerative diseases, mood disorders, schizophrenia, and substance use disorders including alcohol use disorder (AUD; Nam et al., 2013a; Guitart et al., 2016; Viana da Silva et al., 2016; Cheffer et al., 2018). Particularly, DMS $\mathrm{A}_{2 \mathrm{~A}} \mathrm{R}$ regulates the sucrose reward-seeking and sensitivity of reward devaluation, whereas dorsolateral striatum (DLS) $\mathrm{A}_{2 \mathrm{~A}} \mathrm{R}$ does not (Nam et al., 2013b; Li et al., 2016). However, the roles of $\mathrm{A}_{2 \mathrm{~A}} \mathrm{R}$ and $\mathrm{iMSN}$ in ethanol-containing rewardseeking have not been fully investigated.

In this study, we used the ethanol-containing reward to identify how non-preferred ethanol-containing outcome is conditioned as the preferred reinforcer. Thus, we investigated whether operant conditioning with the ethanol-containing reward revaluates conditioned reward over that of a sucrose reward. In addition, we examined whether pre-exposure of ethanol contributes to the appraisal of the conditioned reward. We also identified the electrophysiological traits of the DMS iMSNs in ethanolcontaining reward-seeking behavior. Pharmacologically, we estimated how DMS $\mathrm{A}_{2 \mathrm{~A}} \mathrm{R}$ manipulates seeking behavior toward the conditioned reward. Using optogenetic approaches in $A_{2 A} R$ promoter-driven Cre-expressing mice, we sought to examine the effects of manipulating neuronal activities in the DMS-GPe iMSNs on the ethanol-containing reward-seeking behavior. Our study reveals the roles of DMS $\mathrm{A}_{2 \mathrm{~A}} \mathrm{R}$ and $\mathrm{iMSN}$ in the ethanolcontaining reward-seeking behavior.

\section{Materials and Methods}

\section{Animals}

All experimental procedures were approved by the Mayo Clinic Institutional Animal Care and Use Committee and performed in accordance with $\mathrm{NIH}$ guidelines. We used male adenosine $\mathrm{A} 2 \mathrm{~A}$ receptor $\left(\mathrm{A}_{2 \mathrm{~A}} \mathrm{R}\right.$; Adora2A)-Cre mice (MMRRC: 031168-UCD; C57BL/6J background), dopamine receptor $\mathrm{D} 2\left(\mathrm{D}_{2} \mathrm{R}\right)$ promoter-driven enhanced green fluorescent protein $\left(\mathrm{D}_{2} \mathrm{R}-\mathrm{eGFP}, \mathrm{FVB} / \mathrm{N}\right.$ background) and $\mathrm{C} 57 \mathrm{BL} / 6 \mathrm{~J}$ mice. $\mathrm{A}_{2 \mathrm{~A}} \mathrm{R}$-Cre mice were provided by Dr. Jiang-Fan Chen at Wenzhou Medical University. $\mathrm{D}_{2} \mathrm{R}$-eGFP (stock \#030255) and C57BL/6J mice were purchased from The Jackson Laboratory. Mice were housed in standard Plexiglas cages. The colony room was maintained at a constant temperature $\left(24 \pm 1{ }^{\circ} \mathrm{C}\right)$ and humidity $(60 \pm 2 \%)$ with a $12 \mathrm{~h}$ light/dark cycle (lights on at 07:00 A.M.). We used 8- to 10-week-old male mice for all experiments. Mice were allowed ad libitum access to food and water. For the behavior tests, mice were food restricted to $85 \%$ of their baseline weight, at which time they were maintained for the duration of experimental procedures.

\section{Drugs}

We systemically administered CGS-21680 hydrochloride (CGS; $\mathrm{A}_{2 \mathrm{~A}} \mathrm{R}$ agonist; $0.1 \mathrm{mg} / \mathrm{kg}$, i.p.; Tocris Bioscience) or KW-6002 (KW; $\mathrm{A}_{2 \mathrm{~A}} \mathrm{R}$ antagonist; $1 \mathrm{mg} / \mathrm{kg}$, i.p.; Tocris Bioscience) $30 \mathrm{~min}$ before the behavior test. CGS and KW were dissolved in 10\% DMSO, 10\% Tween $80(\mathrm{v} / \mathrm{v})$ in saline. For microinjection of CGS and vehicle (VEH), we infused them with a microinjection controller (World Precision Instruments) at $1 \mu \mathrm{l} /$ min flow rate for $30 \mathrm{~s}$.

\section{Stereotaxic surgery and virus injection}

Mice were anesthetized with ketamine/xylazine (100 and $7 \mathrm{mg} / \mathrm{kg}$, i.p.) and placed on the digital stereotaxic alignment system (Model 1900, David Kopf Instruments). Hair was trimmed and the skull was exposed using an 8-gauge electrosurgical skin cutter (KLS Martin). The skull was leveled using a dual-tilt measurement tool. Holes were drilled in the skull at the appropriate stereotaxic coordinates. Viruses were infused at 100 $\mathrm{nl} / \mathrm{min}$ for $5 \mathrm{~min}$ through a 35-gauge injection needle (catalog \#NF35BV, World Precision Instruments) using a microsyringe pump (Model UMP3, World Precision Instruments). The injection needle remained in place for an additional 5 min following the end of the injection. For microinjection of drugs, we stereotactically implanted a 26-gauge double-guided cannulae (C235GS-5-2.0/SPC $1 \mathrm{~mm}$; Plastics One) targeting into the DMS (AP: $+0.5 \mathrm{~mm}, \mathrm{ML}: \pm 1.0 \mathrm{~mm}, \mathrm{DV}:-1.0 \mathrm{~mm}$ from the brain surface). An internal cannula (33 gauge) extended $1 \mathrm{~mm}$ beyond the guide cannula. The cannula was fixed to the skull using dental cement. Following stereotaxic surgery, mice were allowed to recover 1 week before the experiment. We referred to the literature (Paxinos and Franklin, 2001) for the coordination and modified brain maps. We received permission from Elsevier.

\section{Viruses}

Viruses were purchased from the UNC vector core. We injected viruses at the following titers: AAV5-EF1 $\alpha$-DIO-eYFP, $6.0 \times 10^{12} \mathrm{GC} /$ $\mathrm{ml}$; AAV5-EF1 $\alpha$-DIO-hChR2-eYFP, $6.6 \times 10^{12} \mathrm{GC} / \mathrm{ml}$; AAV5-EF1 $\alpha$ DIO-eNpHR3.0-eYFP, $3.1 \times 10^{12} \mathrm{GC} / \mathrm{ml}$.

\section{Behavioral experiments}

Operant conditioning. We used the operant-conditioned chambers the same as the apparatus in our previous study (Nam et al., 2013b). Mice were placed in operant chambers with two interactive nose holes ("active" and "inactive"; Med Associates) in which they poke a single hole for an outcome of the conditioned reward [10 $\mu$ l of 10\% sucrose and $10 \%$ ethanol in tap water per reinforcer (10E10S)] or the sucrose reward [10 $\mu \mathrm{l}$ of $10 \%$ sucrose (10S); only for Fig. 2]. On the first day, mice were trained to approach the magazine in each schedule on a random time schedule (average $30 \mathrm{~s}$ ) with a reward delivered for $30 \mathrm{~min}$. Next, mice were trained in a continuous reinforcement (CRF) for three $1 \mathrm{~h}$ sessions. After acquiring nose-poking behavior, mice were trained on a random interval (RI30 $1 \mathrm{~d}$ and RI60 $2 \mathrm{~d}$ ) schedule for $30 \mathrm{~min}$. In the CRF schedule, the reinforcer followed one time of the correct action (active nose-poke). In the RI30/60 schedule, the reinforcer followed that random amount of time (average 30 or $60 \mathrm{~s}$ ) had passed after the correct action (active nose-poke). If mice poked active nose hole an average of 30/60 s before the outcome presentation, that nose-poke was unrewarded. After obtaining reward outcome, if mice showed active nose-poking before next reward outcome presentation, elapsed time became " 0 " and mice needed to wait an average of 30/60 s again to get reward outcome. Figure $1 \mathrm{~A}$ describes these schedules. Inactive nose-poke as a control did not deliver the reinforcer. Latency to magazine indicates the latency time from nosepoking the hole to approaching the magazine. Among 173 mice used for operant conditioning all together with different cohorts, we excluded 10 of them with the criteria (average latency to magazine $>2 \mathrm{~s}$ at the third CRF session). After the selection, we included all the mice for reward evaluation without exclusion.

Evaluation test. On the evaluation session, mice were given $1 \mathrm{~h}$ of ad libitum access to the outcome previously earned by nose-poke (devalued state), or tap water (neutral state) and then underwent the extinction test for $10 \mathrm{~min}$. The order of schedule exposure during testing was the same as conditioning exposure with the order of valuation session counterbalanced across mice. Twenty-four hours after the evaluation test, we used mice for the electrophysiology experiments. The ratio between (neutral $\rightarrow$ devalued states) and (devalued $\rightarrow$ neutral states) was the same.

Locomotor activity test. The open-field test was conducted in chambers (Med Associates). For the effects of CGS on locomotion, locomotor responses of mice were recorded for $30 \mathrm{~min}$. For the effects of $473 \mathrm{~nm}$ laser stimulation on locomotion, total distance traveled was recorded for 40 min. Locomotion was measured using beam breaks.

Three-arm choice test. To simultaneously examine preference of three kinds of liquid, we put water, 10S, and $10 \mathrm{~S}+10 \%$ ethanol solutions on the Y-maze. The length of each arm was $34 \mathrm{~cm}$ and we assigned each zone in the place from half arm to the arm endpoint. We put mice on the center area of Y-maze and recorded their movement for $15 \mathrm{~min}$ by using the video-tracking system with EthoVision XT software (Noldus). 
A

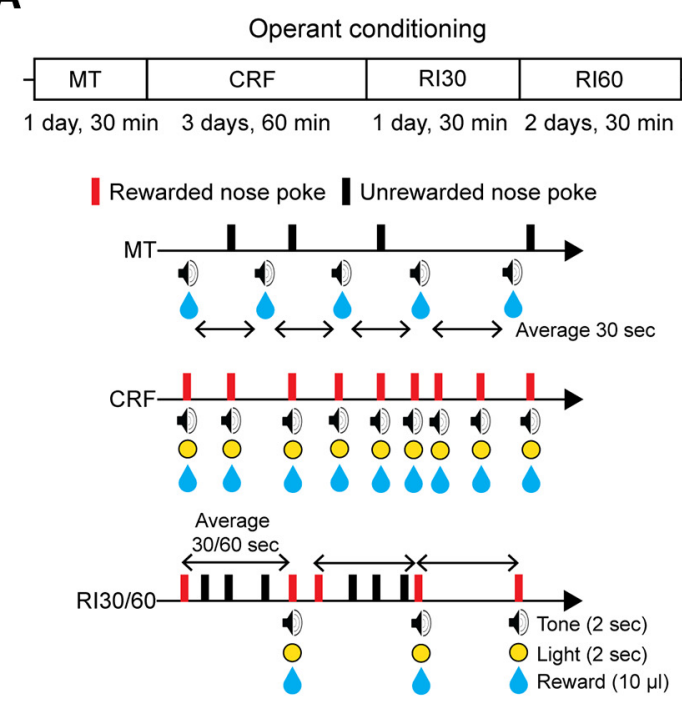

E

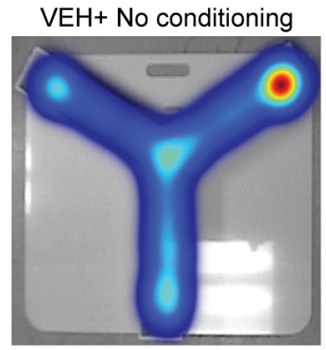

$\mathbf{F}$

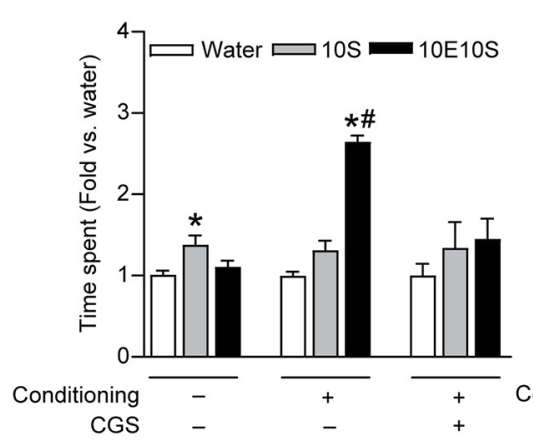

G
B

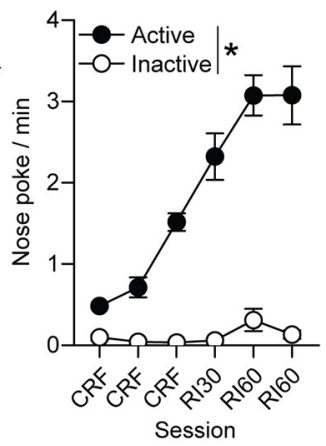

D

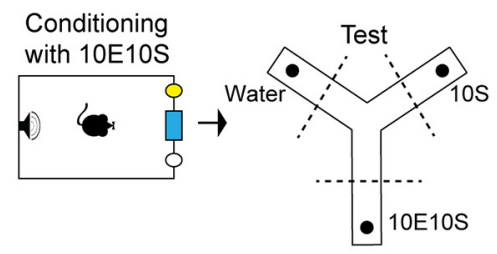

C

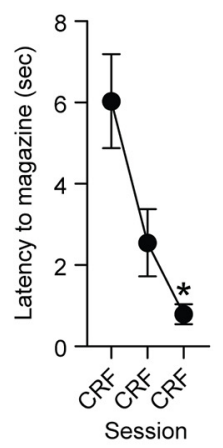

VEH + Conditioning
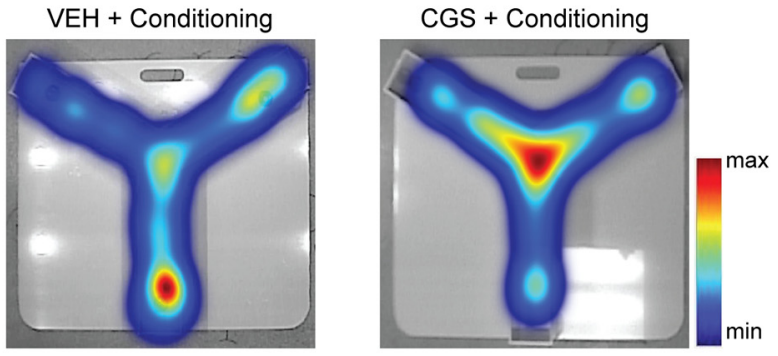

H

Figure 1. Effects of operant conditioning and $\mathrm{A}_{2 \mathrm{~A}}$ R activation on the preference of ethanol-containing reward in male $C 57 \mathrm{BL} / 6 \mathrm{~J}$ mice. $\boldsymbol{A}$, Experimental scheme. $\boldsymbol{B}$, Nose-poking behavior and $(\boldsymbol{C})$ latency to the magazine during the sessions ( $n=14 /$ group). $\boldsymbol{D}$, We presented tap water, $10 \mathrm{~S}$, and 10E10S on each arm of the $Y$-maze. $\boldsymbol{E}$, The heat map displays mice tracking patterns for 15 min on the $Y$-maze. $\boldsymbol{F}$, Time spent and $(\boldsymbol{G})$ zone entries of each arm, and $(\boldsymbol{H})$ total distance traveled for 15 min in the $Y$-maze $\left(n=10 /\right.$ group). Data represented as mean $\pm \mathbf{S E M}$. ${ }^{*} p<0.05$, comparing $(\boldsymbol{B})$ active and inactive nose-poke, $(\boldsymbol{C})$ first CRF session, $(\boldsymbol{F}, \boldsymbol{G})$ the water zone of the same treatment group; ${ }^{\#} p<0.05$ comparing the 105 zone of the same treatment group. $\boldsymbol{B}$, Two-way repeatedmeasures ANOVA followed by Bonferroni's multiple-comparisons test, $(\boldsymbol{C}, \boldsymbol{F}, \boldsymbol{G})$ one-way repeated-measures ANOVA followed by Tukey's multiple-comparisons test $(\boldsymbol{H})$ one-way ANOVA followed by Tukey's multiple-comparisons test. MT, Magazine training; CGS, $0.1 \mathrm{mg} / \mathrm{kg}$, i.p.

Spontaneous alternation behavior in $Y$-maze test. We positioned mice within one arm facing the endpoint wall. The sequence and number of arm entries were recorded for $5 \mathrm{~min}$ by using a video-tracking system (EthoVision XT software, Noldus). The spontaneous alternation (\%) was defined as the number of alternations divided by the number of the combination of sequent three arm entries and multiplied by 100: spontaneous alternation $(\%)=[$ (the number of alternations $) /($ total arm entries -2$)] \times 100$.

\section{Optogenetics}

Evaluation test. A $473 \mathrm{~nm}$ laser was used to deliver unilateral optogenetic stimulation of channelrhodopsin-2 (ChR2). A $593 \mathrm{~nm}$ laser was used to deliver unilateral optogenetic inhibition through enhanced halorhodopsin (eNpHR). While mice freely moved in the operant conditioned chamber for $10 \mathrm{~min}$, the light was delivered using a $2 \mathrm{~ms}$ pulse width, 10 $\mathrm{Hz}$, and $\sim 3 \mathrm{~mW}$ of power measured at the end face of $200 \mu \mathrm{m}$ optical fiber.

Locomotor activity test. A $473 \mathrm{~nm}$ laser was delivered into the DMS treated with either AAV5-EF1 $\alpha$-DIO-eYFP or AAV5-EF1 $\alpha$-DIOhChR2-eYFP. Fifteen minutes after the test started, the light was given to the mice every $10 \mathrm{~min}$ for $5 \mathrm{~min}$. Light intensity and features were the same as those in the evaluation test.

\section{Repeated intermittent ethanol exposure}

The intermittent ethanol paradigm has been described previously (Ayers-Ringler et al., 2016). Briefly, mice were exposed to ethanol vapor or room air using vapor administration chambers (La Jolla Alcohol Research) for $16 \mathrm{~h}$, followed by $8 \mathrm{~h}$ of room air in their home cages. This 
process was repeated for 4 consecutive days, followed by $3 \mathrm{~d}$ in their home cages with room air. Ethanol was vaporized by pumping 95\% ethanol into a flask to mix the vaporized ethanol with room air, continuously pumping the mixture into the chambers to maintain a concentration of 3.0-5.0 $\mathrm{mg}$ ethanol/L of air. Air control chambers received identical airflow rates from room air. Before each vapor exposure, mice were treated with $1.5 \mathrm{~g} / \mathrm{kg}$ ethanol (20\% v/v in $0.9 \%$ saline) or saline and 68.1 $\mathrm{mg} / \mathrm{kg}$ pyrazole (Sigma-Aldrich) in a single intraperitoneal injection to help initiate ethanol intoxication and maintain stable blood ethanol concentrations (BACs). After injections, mice were immediately placed inside the vapor chambers with food and water ad libitum. Immediately after the last session of ethanol exposure, BAC was $209.2 \pm 16.2 \mathrm{mg} / \mathrm{dl}$ (0.2 $\mathrm{g} \%$ or $43.4 \mathrm{~mm}$ ) using the Analox AM1 BAC measuring system (Analox Instruments), which are physiologically relevant BAC in both human and rodent studies (Savola et al., 2004; Ayers-Ringler et al., 2016; Aoun et al., 2018; Renteria et al., 2018).

\section{Immunofluorescence}

Brains were fixed with $4 \%$ paraformaldehyde (Sigma-Aldrich) and transferred to $30 \%$ sucrose (Sigma-Aldrich) in PBS at $4^{\circ} \mathrm{C}$ for $72 \mathrm{~h}$. Brains were then frozen in dry ice and sectioned at $40 \mu \mathrm{m}$ using a microtome (Leica). Brain slices were stored at $-20^{\circ} \mathrm{C}$ in a cryoprotectant solution containing $30 \%$ sucrose, $30 \%$ ethylene glycol in PBS. Sections were incubated in $0.2 \%$ Triton X-100, 5\% bovine serum albumin in PBS for $1 \mathrm{~h}$ followed by three times of washing with PBS. The sections were mounted onto a glass slide coated with gelatin and coverslipped with a mounting solution. Images were obtained using an LSM 700 laser scanning confocal microscope (Carl Zeiss).

\section{Brain slice preparation and electrophysiology}

Mice were deeply anesthetized by inhalation of isoflurane and the brain was rapidly removed and placed in ice-cold sucrose-based artificial CSF (aCSF) containing the following (in $\mathrm{mm}$ ): 210 sucrose, $2.5 \mathrm{KCl}, 1.25$ $\mathrm{NaH}_{2} \mathrm{PO}_{4}, 1 \mathrm{MgCl}_{2}, 2 \mathrm{CaCl}_{2}, 25 \mathrm{NaHCO}_{3}, 0.3$ l-ascorbate, and 10 glucose, and oxygenated with $95 \% \mathrm{O}_{2} / 5 \% \mathrm{CO}_{2}$. Coronal $(300 \mu \mathrm{m})$ or sagittal (400 $\mu \mathrm{m}$ thick) slices were cut with a vibrating microtome (Leica), then transferred to a holding chamber and incubated for $30 \mathrm{~min}$ at $34^{\circ} \mathrm{C}$ and kept at least for $1 \mathrm{~h}$ at room temperature $\left(24-25^{\circ} \mathrm{C}\right)$ in carbonated ( $95 \% \mathrm{O}_{2} / 5 \% \mathrm{CO}_{2}$ ) standard aCSF containing the following (in $\mathrm{mm}$ ): 126 $\mathrm{NaCl}, 2.5 \mathrm{KCl}, 1.25 \mathrm{NaH}_{2} \mathrm{PO}_{4}, 1 \mathrm{MgCl}_{2}, 2 \mathrm{CaCl}_{2}, 25 \mathrm{NaHCO}_{3}$, and 10 glucose. After equilibration, a single slice was transferred to a submersion-type recording chamber and mechanically stabilized with an anchor (Warner Instruments).

Electrical signals were acquired with an Axon 700B amplifier, a Digidata 1550B A/D converter, and Clampex 11.0 and analyzed with Clampfit 11.0 software (Molecular Devices). Throughout the experiments, the bath was continually perfused with warm $\left(32^{\circ} \mathrm{C}\right)$ carbonated aCSF $(2.0-$ $2.5 \mathrm{ml} / \mathrm{min}$ ). Patch pipettes had a resistance of $6-8 \mathrm{M} \Omega$ when filled with a solution containing the following (in mM): $130 \mathrm{~K}$-methanesulfonate, 10 $\mathrm{KCl}, 4 \mathrm{NaCl}, 10 \mathrm{HEPES}$, 0.5 EGTA, $2 \mathrm{MgATP}$, and $0.2 \mathrm{Na}_{2} \mathrm{GTP}$ for current clamping; $140 \mathrm{~K}$-gluconate, $5 \mathrm{KCl}, 2 \mathrm{MgCl}_{2}, 10 \mathrm{HEPES}, 2$ MgATP, and $0.2 \mathrm{Na}_{2} \mathrm{GTP}$ for current clamping; and $140 \mathrm{Cs}-$ methanesulfonate, $5 \mathrm{KCl}, 2 \mathrm{MgCl}_{2}, 10 \mathrm{HEPES}, 2 \mathrm{MgATP}$, and 0.2 $\mathrm{Na}_{2} \mathrm{GTP}$ for voltage clamping. The $\mathrm{pH}$ was adjusted to 7.2 with Tris-base and the osmolarity to $310 \mathrm{mOsm} / \mathrm{L}$ with sucrose. The iMSN neurons were identified with GFP color and electrophysiological properties (Calabresi et al., 1998; Tozzi et al., 2011). The spontaneous firing was recorded using the loose-patch cell-attached technique. Miniature EPSCs (mEPSCs) were recorded in the presence of tetrodotoxin $(0.5$ $\mu \mathrm{M})$. Evoked EPSCs (eEPSCs) were elicited through a bipolar electrode placed $200 \mu \mathrm{m}$ from the recording site. Access resistance was monitored by a step of $-10 \mathrm{mV}(0.1 \mathrm{~Hz})$ and experiments were discarded if the access resistance increased $>20 \%$. The charge transfer was calculated by integrating the area under the EPSC waveform. Neuronal excitability was examined in the whole-cell mode, and $50 \mathrm{pA}$ current steps (from -300 to $300 \mathrm{pA}$ ) were applied, from which $V-I$ plots were determined (the number of action potential vs current). Evoked EPSCs were confirmed with AMPA receptor antagonist DNQX $(20 \mu \mathrm{M})$ and NMDA receptor antagonist AP5 $(50 \mu \mathrm{M})$. To record optogenetic responses, we delivered trains of $2 \mathrm{~ms}$ blue light pulses with frequency at 1, 2, 5, 10, 20, 50, and $100 \mathrm{~Hz}$. Light-evoked IPSCs (oIPSCs) were recorded by a single $10 \mathrm{~ms}$ pulse at a holding potential of $+40 \mathrm{mV}$ and confirmed with a $\mathrm{GABA}_{\mathrm{A}}$ receptor antagonist (picrotoxin, $100 \mu \mathrm{M}$ ).

\section{Statistical analysis}

All data represented as the mean \pm SEM and were analyzed by unpaired/ paired two-tailed Student's $t$ tests, one-way ANOVA/repeated measures one-way ANOVA followed by Tukey's multiple-comparisons tests, and two-way ANOVA/repeated-measures ANOVA followed by Bonferroni's multiple-comparisons tests using Prism 7.0 (GraphPad Software). Statistical significance was set at $p<0.05$.

\section{Results}

\section{$A_{2 A} R$ activation reduces operant}

\section{conditioning-induced revaluation}

Because it is difficult to initiate ethanol-seeking behaviors with ethanol itself in mice, chronic ethanol adaptation, sucrose fading, or water/food restriction are commonly used in operant conditioning (Corbit et al., 2012; Noronha, 2014; Ron and Barak, 2016; Laguesse et al., 2017; Blegen et al., 2018). In this study, we used an operant-conditioning method with random interval (RI) to reinforce toward ethanol-containing reward. As illustrated in Figure $1 A$, we trained mice with RI30 for $1 \mathrm{~d}$ and followed by RI60 for $2 \mathrm{~d}$ schedules after acquiring nose-poking behavior in the CRF schedule. The RI schedule yields consistently a conditioned reward-seeking behavior (Yin and Knowlton, 2006; Gesiarz and Crockett, 2015). As we described in Materials and Methods, only $\sim 5 \%$ of mice were excluded for failure of being conditioned with $10 \mathrm{E} 10 \mathrm{~S}$ solution (10/173 from all the experiments). During the conditioning sessions, mice progressively preferred the active hole compared with the inactive hole (Fig. $1 B$; interaction between active/ inactive nose-poke and sessions: $\left.F_{(1,26)}=135.8, p<0.001\right)$ and showed the reduced latency to magazine compared with the first CRF session (Fig. $1 C ; F_{(1.559,20.26)}=9.883, p=0.002$ ).

Using the $\mathrm{Y}$-maze, we examined whether $\mathrm{A}_{2 \mathrm{~A}} \mathrm{R}$ contributes to the preference of $10 \mathrm{~S}$ or $10 \mathrm{E} 10 \mathrm{~S}$ depending on innate preference or operant conditioning (Fig. 1D). First, without any conditioning, naive mice were placed on the Y-maze to test their preference among water, 10S, and 10E10S. Interestingly, naive mice spent more time (Fig. $1 E, F ; F_{(1.934,17.41)}=5.044, p=0.047$ ) in the $10 \mathrm{~S}$ zone and frequently visited the $10 \mathrm{~S}$ zone (Fig. $1 G ; F_{(1.564,14.08)}=$ $14.7, p=0.004)$ compared with the water zone, indicating that non-conditioned mice innately preferred sucrose over ethanolcontaining solution. However, mice operant conditioned with the 10E10S spent more time in the 10E10S zone (Fig. 1F; $\left.F_{(1.376,12.38)}=90.57\right)$ compared with both the 10S $(p<0.001)$ and the water zones $(p<0.001)$. Also, those mice entered more frequently in the 10E10S zone compared with the water zone (Fig. $\left.1 G ; F_{(1.564,14.07)}=19.04, p=0.002\right)$. Additionally, mice conditioned with the 10E10S exhibited increased 10 S zone entries compared with the water zone (Fig. $1 G ; p<0.001$ ). However, $\mathrm{A}_{2 \mathrm{~A}} \mathrm{R}$ agonist CGS $(0.1 \mathrm{mg} / \mathrm{kg}$, i.p.) treatment after operant conditioning abolished differences in the time spent (Fig. $1 F ; F_{(1.536,13.83)}=$ $0.750, p=0.457)$ and zone entries (Fig. $1 G ; F_{(1.187,10.68)}=1.935$, $p=0.194)$ without altering locomotive activity (Fig. $1 H ; F_{(2,27)}=$ 2.038, $p=0.150)$. These results indicate that $\mathrm{A}_{2 \mathrm{~A}} \mathrm{R}$ activation abolished the value of operant conditioned ethanol-containing reward.

\section{Conditioning with the sucrose reward did not increase the preference of the ethanol-containing outcome}

To validate the effect of the operant conditioning on the revaluation, mice were conditioned to 10 S only (Fig. $2 A, B$ ). These mice 
A

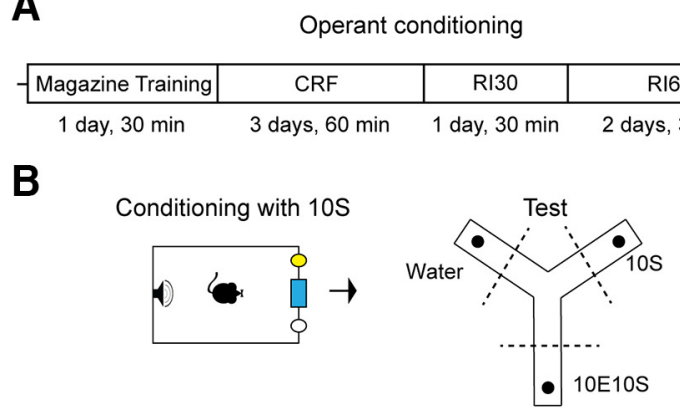

C

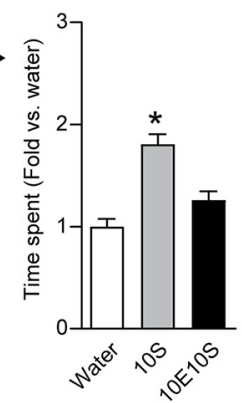

D

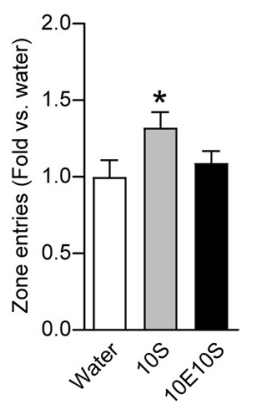

Figure 2. Effects of operant conditioning with the sucrose reward on the preference of ethanol-containing outcome in the Y-maze. $\boldsymbol{A}, \boldsymbol{B}$, Experimental scheme. $\boldsymbol{C}$, Time spent and ( $\boldsymbol{D})$ zone entries of each arm of the Y-maze for $15 \mathrm{~min}\left(n=9 /\right.$ group). Data are represented as mean $\pm \mathrm{SEM} .{ }^{*} p<0.05$, comparing the water zone of the same treatment group. One-way repeated-measures ANOVA followed by Tukey's multiple-comparisons test.

A

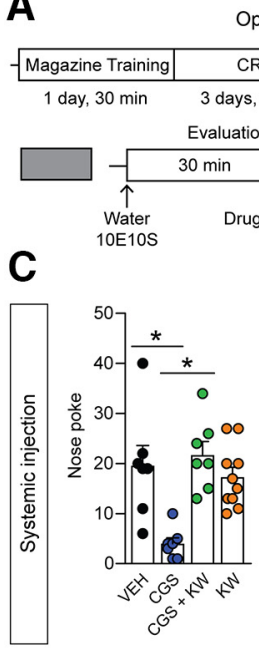

Operant conditioning

uation in home cage Extinction test

D

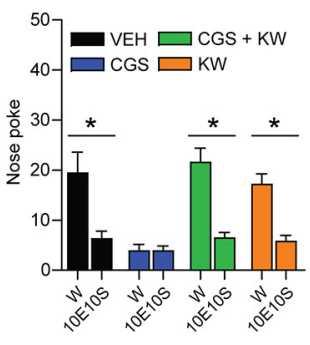

Evaluation test

B

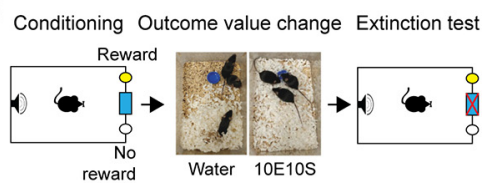

E

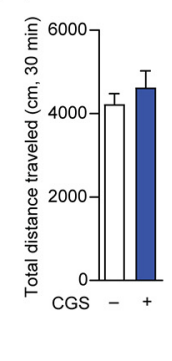

F

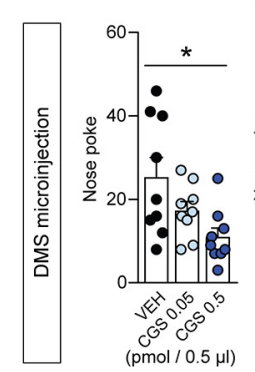

G

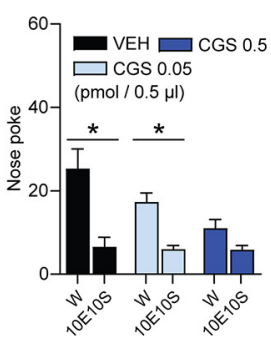

Figure 3. Effects of pharmacological $A_{2 A} R$ modulations in ethanol-containing reward-seeking in C57BL/6J mice. $A, B$, Experimental scheme. C, Effects of CGS $(0.1 \mathrm{mg} / \mathrm{kg}$, i.p.), KW (1 mg/kg, i.p.), or CGS + KW on nose-poke in water presentation. D, G, Nose-poking changes between water (W) and 10E10S presentations. $E$, Effects of CGS $(0.1 \mathrm{mg} / \mathrm{kg}$, i.p.) on total distance traveled for $30 \mathrm{~min}$ in the open-field. $\boldsymbol{F}$, Effects of DMS microinjections of CGS $(0.05,0.5 \mathrm{pmol} / 0.5 \mu \mathrm{l})$ on nose-poke in water presentation. Data represented as mean $\pm \mathrm{SEM}$; (C, D) $n=7 / \mathrm{VEH}$, CGS, CGS $+\mathrm{KW}$ groups, $n=10 / \mathrm{KW}$ group; $(\boldsymbol{E}) n=9 /$ group; $(\boldsymbol{F}, \boldsymbol{G}) n=9 /$ group. ${ }^{*} p<0.05$, comparing each group. $\boldsymbol{C}, \boldsymbol{F}, 0$ ne-way ANOVA followed by Tukey's multiple-comparisons test, $(\boldsymbol{D}, \boldsymbol{G})$ paired Student's $t$ test, $(\boldsymbol{E})$ unpaired Student's $t$ test.

showed longer time spent (Fig. $2 C ; F_{(1.718,13.75)}=90.57, p=$ 0.002 ) and increased zone entries (Fig. $2 D ; F_{(1.844,14.75)}=8.774$, $p=0.004)$ in the $10 \mathrm{~S}$ zone compared with those of the water zone, but not in the 10E10S zone $(p>0.05)$, indicating that the operant conditioning with the sucrose reward did not change the value of the ethanol-containing solution.

\section{Effects of pharmacological modulations of $A_{2 A} R$ on conditioned reward-seeking}

To examine the role of $\mathrm{A}_{2 \mathrm{~A}} \mathrm{R}$ in the evaluation of conditioned reward, we used the evaluation test using outcome value change (water presentation as the neutral state; 10E10S presentation as the devalued state) followed by the extinction test (Fig. $3 A, B$ ). We examined the effects of $\mathrm{A}_{2 \mathrm{~A}} \mathrm{R}$ agonists on the ethanolcontaining reward-seeking behavior. Interestingly, systemic injection $(0.1 \mathrm{mg} / \mathrm{kg}$, i.p.) of CGS decreased nose-poking behavior compared with the VEH group in the water presentation (Fig. 3C; $F_{(3,27)}=8.767, p=0.002$; ) without significant changes in locomotive activity (Fig. $3 E ; t=0.846, p=0.410)$. Additionally, $\mathrm{A}_{2 \mathrm{~A}} \mathrm{R}$ activation did not show a significant difference in nose-poke between water and $10 \mathrm{E} 10 \mathrm{~S}$ presentations (Fig. $3 D ; t=0, p>0.999$ ), whereas the VEH group showed a significant difference in nosepoke (Fig. $3 D ; t=3.375, p=0.015$ ).

We also coinjected both an $\mathrm{A}_{2 \mathrm{~A}} \mathrm{R}$ agonist and an antagonist to examine the direct contribution of $\mathrm{A}_{2 \mathrm{~A}} \mathrm{R}$ to reward evaluation. Because $\mathrm{A}_{2 \mathrm{~A}} \mathrm{R}$ antagonist has a different binding pocket than the $A_{2 A} R$ agonist (Lebon et al., 2011), we sought to examine whether the coinjection diminishes or abolishes the effects of $\mathrm{A}_{2 \mathrm{~A}} \mathrm{R}$ activation. Coadministration of the CGS $(0.1 \mathrm{mg} / \mathrm{kg}$, i.p.) and the selective antagonist $\mathrm{KW}(1 \mathrm{mg} / \mathrm{kg}$, i.p.) increased nose-poking behaviors in the water presentation compared with the CGS alone treatment group (Fig. $3 C ; p<0.001$ ). In addition, a combination of the $\mathrm{A}_{2 \mathrm{~A}} \mathrm{R}$ agonist and antagonist displayed a significant difference of nose-poke between water and 10E10S presentations (Fig. 3D; $t=7.104, p<0.001)$. KW (1 mg/kg, i.p.) alone showed similar nose-poking behaviors to those of the VEH group (Fig. $3 C: F_{(3,27)}=8.767, p=0.916 ; 3 D: t=4.601, p=$ $0.001)$.

Consistent with the effects of systemic $\mathrm{A}_{2 \mathrm{~A}} \mathrm{R}$ activation, intraDMS microinjection $(0.5 \mathrm{pmol} / 0.5 \mu \mathrm{l})$ of CGS also showed significant decreases in nose-poking behavior compared with the VEH group in the water presentation (Fig. $3 F ; F_{(2,24)}=4.909, p=$ 
A
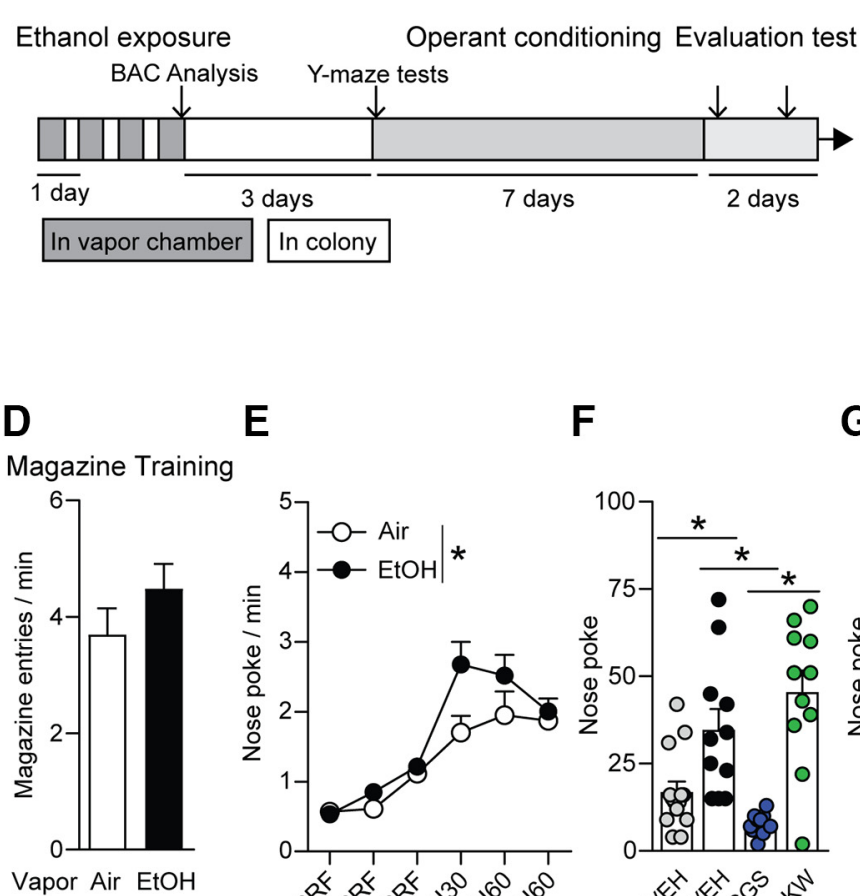

$\mathbf{E}$

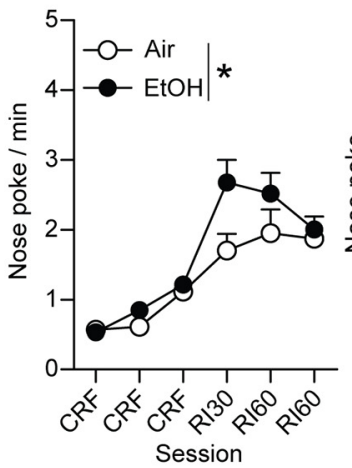

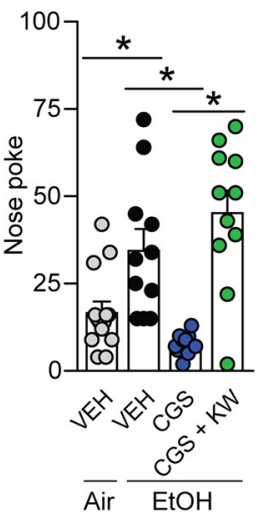

B

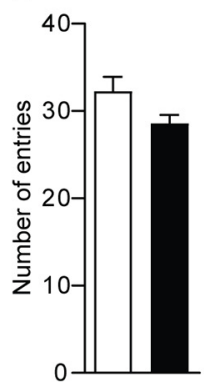

G

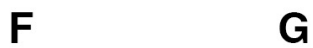

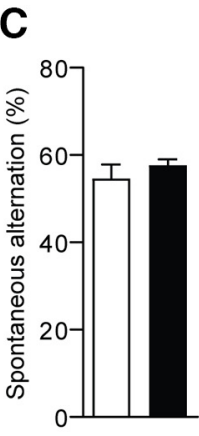

Vapor Air EtOH

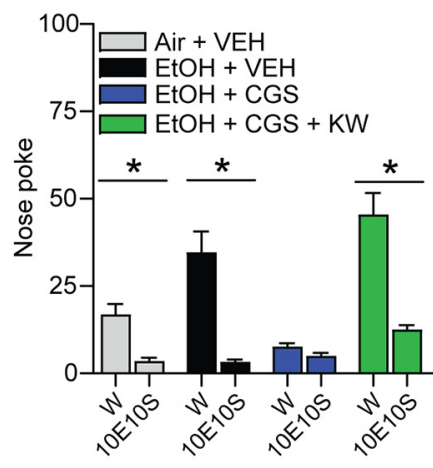

Figure 4. Effects of ethanol pre-exposure with $A_{2 A} R$ activation on ethanol-containing reward-seeking in $(57 \mathrm{BL} / 6 \mathrm{~J}$ mice. $\boldsymbol{A}$, Behavior schedule. $\boldsymbol{B}$, The number of entries, and $(\boldsymbol{C})$ spontaneous alternation (\%) in the Y-maze. $\boldsymbol{D}$, Magazine entries in the magazine training session and $(\boldsymbol{E})$ differences of nose-poking behavior during operant conditioning between air and ethanol vapor exposure. $\boldsymbol{F}$, Effects of ethanol pre-exposure and pharmacological $A_{2 A} R$ modulations (CGS: $0.1 \mathrm{mg} / \mathrm{kg}$, i.p.; $K W: 1 \mathrm{mg} / \mathrm{kg}$, i.p.; or CGS + KW) on nose-poke in water presentation. $\boldsymbol{G}$, Nose-poking changes between water (W) and 10E10S presentations. Data represented mean $\pm \operatorname{SEM} ;(\boldsymbol{B}, \boldsymbol{C}) n=11$ /air group, $n=22 /$ ethanol group; $(\boldsymbol{D}, \boldsymbol{E}) n=16 /$ air group, $n=29 /$ ethanol group; $(\boldsymbol{F}, \boldsymbol{G}) n=$ 14/air + VEH group; $n=11 /$ ethanol + VEH group; $n=11$ /ethanol + CGS group; $n=11 /$ ethanol + CGS + KW group. ${ }^{*} p<0.05$, comparing each group. $\boldsymbol{B}-\boldsymbol{D}$, Unpaired Student's $t$ test, $(\boldsymbol{E})$ two-way repeated-measures ANOVA followed by Bonferroni's multiple-comparisons test, $(\boldsymbol{F})$ one-way ANOVA followed by Tukey's multiple-comparisons test, $(\boldsymbol{G})$ paired Student's $t$ test.

0.012 ) and did not show significant nose-poking changes between the two presentations (Fig. $3 G ; t=1.998, p=0.081$ ). On the other hand the VEH group showed significant difference in nose-poke (Fig. $3 G$; $t=3.863, p=0.005$ ). Therefore, these results suggest that DMS $\mathrm{A}_{2 \mathrm{~A}} \mathrm{R}$ activity is important for regulating ethanol-containing conditioned reward-seeking behavior.

\section{Ethanol exposure potentiates $\mathrm{A}_{2 \mathrm{~A}} \mathrm{R}$-dependent conditioned reward-seeking}

We next sought to examine whether ethanol pre-exposure contributes to the operant conditioning-induced revaluation (Fig. $4 A$ ). Ethanol exposure did not alter the number of entries (Fig. $4 B ; t=2.025, p=0.052$ ) and spontaneous alternation (Fig. 4C; $t=0.019, p=0.316)$ in the Y-maze after $3 \mathrm{~d}$ of withdrawal following the four sessions of ethanol exposure in the vapor chamber. Moreover, ethanol exposure showed the similar number of magazine entries during magazine training (Fig. 4D; $t=$ $1.061, p=0.297$ ). However, ethanol exposure increased rewardseeking behavior toward the conditioned reward (Fig. 4E; the interaction between treatment and sessions: $F_{(5,215)}=2.442, p=$ $0.035)$. Additionally, ethanol exposure increased the nose-poking behavior compared with the air group in the water presentation (Fig. $\left.4 F ; F_{(3,43)}=14.69, p=0.025\right)$. Also, both air $(t=4.316, p=$ $0.001)$ and ethanol $(t=5.447, p<0.001)$ exposure with $\mathrm{VEH}$ treatment groups showed significant differences between water and 10E10S presentations (Fig. 4G).
We then examined the role of $\mathrm{A}_{2 \mathrm{~A}} \mathrm{R}$ using pharmacological agents. As predicted, CGS (0.1 mg/kg, i.p.) decreased the effects of ethanol vapor on nose-poking behaviors in the water presentation (Fig. $4 F ; p=0.001$ ) and abolished the nose-poking difference between the water and 10E10S presentations (Fig. 4G; $t=$ $1.936, p=0.082$ ). However, intraperitoneal cotreatments of the $\mathrm{A}_{2 \mathrm{~A}} \mathrm{R}$ agonist and antagonist (CGS $0.1 \mathrm{mg} / \mathrm{kg}+\mathrm{KW} 1 \mathrm{mg} / \mathrm{kg}$ ) restored the nose-poking behavior compared with that of the CGS alone treatment group in the water presentation (Fig. 4F; $p<0.001)$ as well as the difference in nose-poking behavior between the water and 10E10S presentations (Fig. $4 G ; t=5.281$, $p<0.001)$. Therefore, these results suggest that ethanol preexposure may potentiate $\mathrm{A}_{2 \mathrm{~A}} \mathrm{R}$-dependent revaluation of the conditioned reward.

\section{$\mathrm{A}_{2 \mathrm{~A}} \mathrm{R}$ activation-induced DMS iMSNs excitation in conditioned reward revaluation}

$\mathrm{A}_{2 \mathrm{~A}} \mathrm{R}$ is known to coexpress with $\mathrm{D}_{2} \mathrm{R}$ in the striatal iMSNs (Farrell et al., 2013; Oude Ophuis et al., 2014), so we used $D_{2} R$ promoter-driven eGFP-expressing mice (Escande et al., 2016) to investigate whether $\mathrm{A}_{2 \mathrm{~A}} \mathrm{R}$ activation and operant conditioning with the conditioned reward change iMSNs activities in the DMS (Fig. 5A). We found that operant conditioning reduced iMSNs firing in response to the current injection (Fig. $5 B, C ; F_{(2,33)}=$ 5.065, $p=0.012 ; p=0.010$ at $200 \mathrm{pA}, p=0.001$ at $250 \mathrm{pA}, p<$ 0.001 at $300 \mathrm{pA}$ current) without alteration in the resting mem- 
A
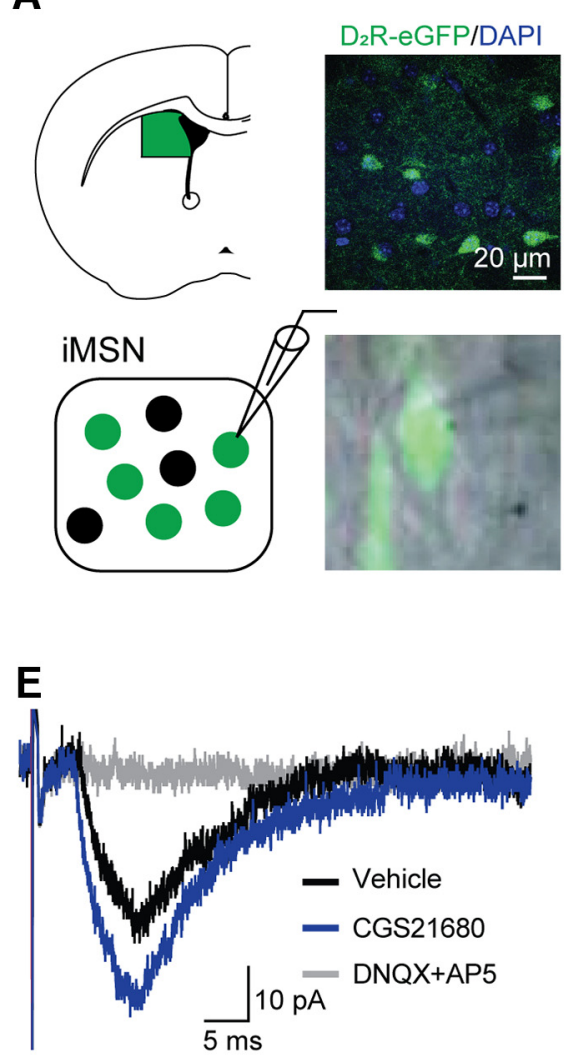

$\mathbf{F}$

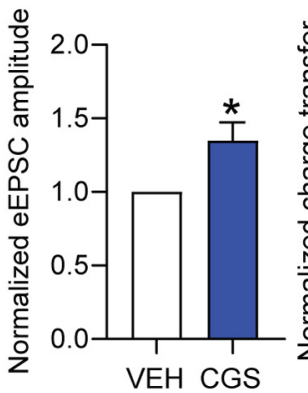

$B$ No conditioning Conditioning Conditioning+CGS

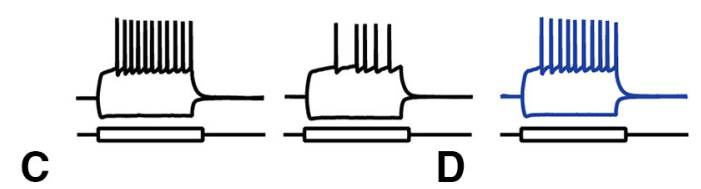

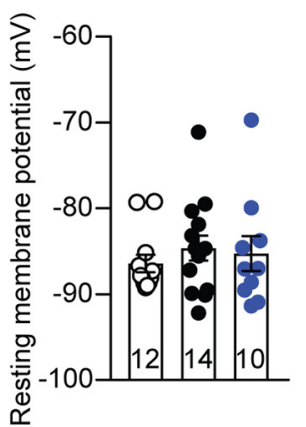

G

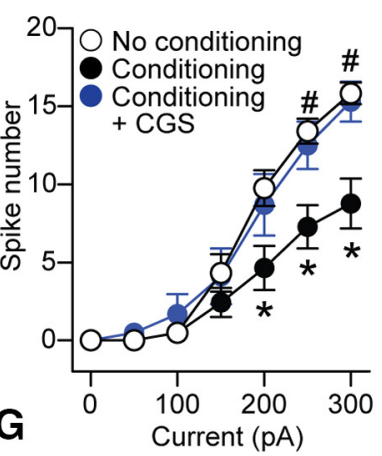

\section{है}

Vehicle
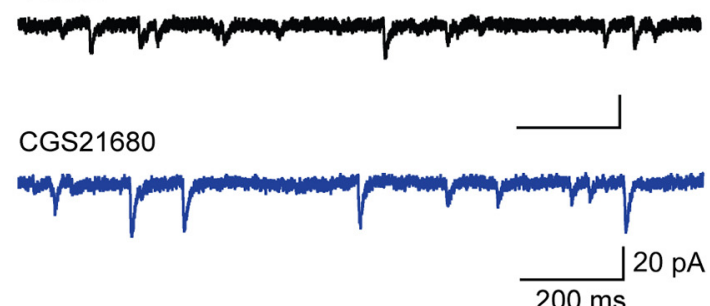

H

$200 \mathrm{~ms}$
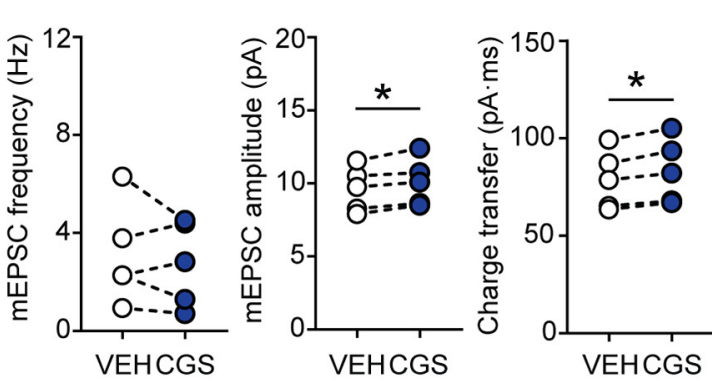

Figure 5. Effects of $A_{2 A} R$ activation on iMSNs activities in the DMS of mice which exhibited ethanol-containing reward-seeking behavior. $A$, Experimental scheme. $D_{2} R$ promoter-driven eGFP (green) and DAPI (blue) in the DMS. DAPI indicates nuclei. Scale bar, $20 \mu \mathrm{m}$. Effects of operant conditioning and CGS (10 $\mu \mathrm{M})$ on $(\boldsymbol{B})$ the traces, $(\boldsymbol{C})$ number of the neuronal spike, and $(\boldsymbol{D})$ the resting membrane potential of the DMS iMSNs. $E, F$, Effects of $A_{2 A} R$ activation on the normalized eEPSC amplitude and charge transfer in the DMS. Black line, VEH treatment; blue line, CGS treatment. The gray line shows AP5 (selective NMDA receptor antagonist; $50 \mu \mathrm{M}$ ) and DNQX (non-NMDA receptor antagonist; $20 \mu \mathrm{m}$ ) treatment group. $\boldsymbol{G}, \boldsymbol{H}$, Effects of $\mathrm{A}_{2 \mathrm{~A}} \mathrm{R}$ activation on mEPSC frequency, amplitude, and charge transfer in the DMS iMSNs. Data represented mean \pm SEM; ${ }^{*} p<0.05(\boldsymbol{C})$ comparing the "no conditioning + VEH group" at the same current point, $(\boldsymbol{F}, \boldsymbol{H})$ comparing the VEH group; $(\boldsymbol{C}) \# p<0.05$ comparing the "conditioning + VEH" group at the same current point. $C$, Two-way ANOVA repeated-measures followed by Bonferroni's multiple-comparisons test, (D) one-way ANOVA followed by Tukey's multiple-comparisons test, $(\boldsymbol{F}, \boldsymbol{H})$ paired Student's $t$ test. $\boldsymbol{C}, \boldsymbol{D}$, No conditioning (12 cells from 5 mice), conditioning (14 cells from 4 mice), conditioning + (GS (10 cells from 4 mice); $(\boldsymbol{F}) 6$ cells from 2 mice; $(\boldsymbol{H}) 5$ cells from 3 mice.

brane potential (Fig. $\left.5 D ; F_{(2,33)}=0.395, p=0.677\right)$ in brain slices prepared $24 \mathrm{~h}$ after the last conditioning session with the conditioned reward in $\mathrm{D}_{2} \mathrm{R}$-eGFP mice. However, $\mathrm{A}_{2 \mathrm{~A}} \mathrm{R}$ agonist CGS $(10 \mu \mathrm{M})$ increased the firing of iMSNs in the DMS of mice which exhibited conditioned reward-seeking (Fig. $5 C ; p=0.014$ at 250 $\mathrm{pA}, p=0.001$ at $300 \mathrm{pA}$ current). CGS treatments also increased the EPSC amplitude (for eEPSCs, Fig. $5 E, F: t=3.114, p=0.026$, VEH $35.52 \pm 9.31 \mathrm{pA}$, CGS $46.64 \pm 13.52 \mathrm{pA}$; for mEPSCs, $5 G, H$ : $t=4.626, p=0.010$ ) and charge transfer (for eEPSCs, Fig. 5F: $t=$ $2.779, p=0.039$; for mEPSCs, $5 H: t=9.846, p=0.001$ ) in the iMSNs, whereas $\mathrm{A}_{2 \mathrm{~A}} \mathrm{R}$ activation did not alter mEPSCs frequency (Fig. $5 H ; t=1.088, p=0.338$ ). These results suggest that operant conditioning with the conditioned reward reduces the capability of neuronal response to stimulation in the DMS iMSNs while $\mathrm{A}_{2 \mathrm{~A}} \mathrm{R}$ activation reverses the reduced neuronal firing.

Optogenetic manipulation-induced changes of electrophysiological features in DMS-GPe iMSNs

Before testing our hypothesis that the manipulation of the iMSNs activities regulates the ethanol-containing reward-seeking, we examined electrophysiological features of DMS-GPe iMSNs using $\mathrm{A}_{2 \mathrm{~A}} \mathrm{R}$-Cre mice. First, we injected Cre-dependent ChR2expressing AAV5 into the DMS of $\mathrm{A}_{2 \mathrm{~A}} \mathrm{R}$-Cre mice and measured electrophysiological features in the DMS (Fig. 6A). We prepared sagittal brain slices containing the striatum and GPe for ex vivo patch-clamp recording, and light stimulation was delivered into 
A

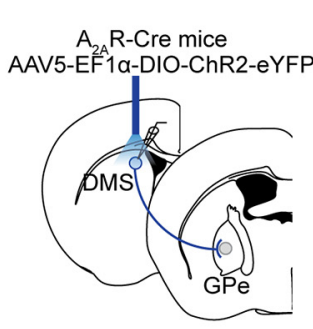

E

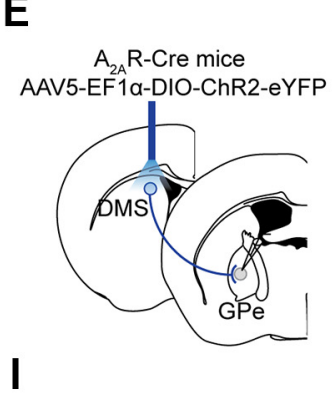

B

$F$

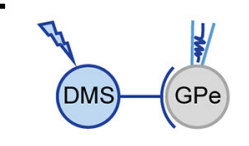

C

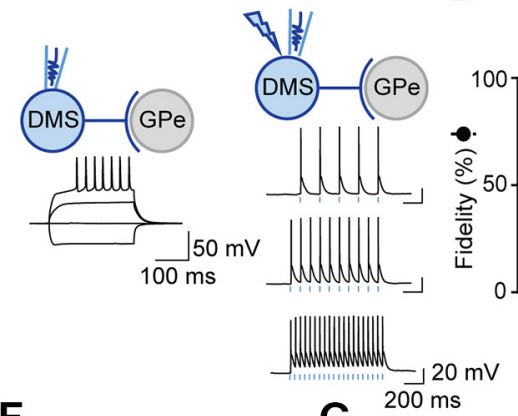

G

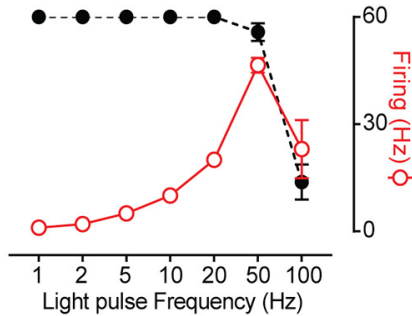

H
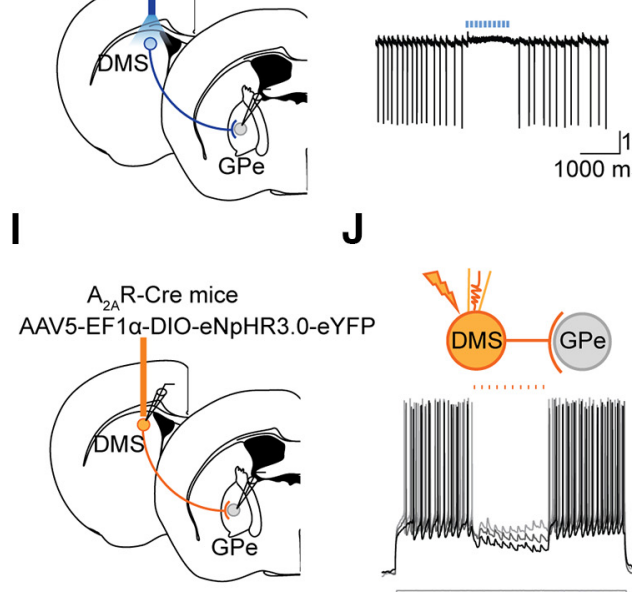

J
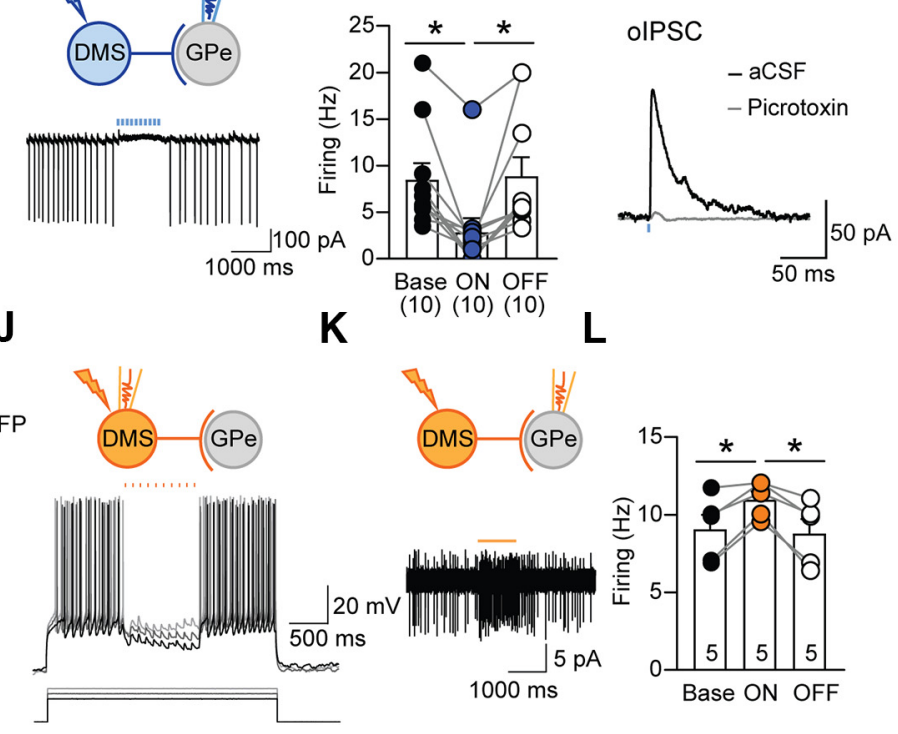

Figure 6. Electrophysiological features of DMS iMSNs. $A, E, I$, Experimental schemes. $B, C$, Neuronal firing without optogenetic stimulation in the $A_{2 A} R$-expressing iMSNs of the DMS. D, Light pulse frequency-dependent change of neuronal firing and fidelity with optogenetic stimulation in the iMSNs of the DMS ( 4 cells from 2 mice). $F, G$, Effects of optogenetic activation of DMS iMSNs on GPe neuronal firing ( $n=10 /$ group from 4 mice). $\boldsymbol{H}$, olPSCs in the GPe of $A_{2 A} R$-Cre mice. Black line, aCSF; gray line, picrotoxin treatment; $G A B A_{A}$ receptor antagonist, $100 \mu$ m. J, Effects of optical inhibition of $A_{2 A} R$-expressing neurons on evoked firing in the DMS. $K, L$, Effects of optical inhibition of DMS $A_{2 A} R$-expressing neurons on the spontaneous firing of the $G P e(n=5 / g r o u p$ from 3 mice). Data are presented mean \pm SEM. ${ }^{*} p<0.05$ comparing each group. $G, L$, One-way repeated-measures ANOVA by Tukey's multiple-comparisons test.

the DMS. DMS ChR2-expressing iMSNs responded to the current injections without light intervention (Fig. 6B), indicating that viral-mediated ChR2 expression does not affect normal iMSNs functions. Optogenetic stimulation with brief blue light evoked action potentials in the iMSNs (Fig. 6C) at frequencies of $1-50 \mathrm{~Hz}$ with high fidelity (Fig. 6D).

Next, we measured electrophysiological features in the GPe (Fig. $6 E$ ). In the randomly patched cells of the medial GPe, blue light stimulation inhibited spontaneous firings $\left(F_{(1.153,10.38)}=\right.$ 13.83; Base vs ON, $p=0.004$; ON vs OFF, $p=0.016$; Fig. $6 F, G$ ). In the whole-cell voltage-clamp mode, blue oIPSCs in the GPe neurons with a latency of $<5 \mathrm{~ms}$, demonstrating direct GABAergic neurotransmission to GPe neurons from DMS iMSNs (Fig. $6 \mathrm{H}$ ). In addition, the oIPSCs were completely abolished by picrotoxin $(100 \mu \mathrm{M})$, indicating that these responses were mediated by GABA released from the axon terminals of iMSNs and postsynaptic $\mathrm{GABA}_{\mathrm{A}}$ receptors on GPe neurons (Fig. $6 \mathrm{H}$ ).

In addition, we injected the Cre-dependent eNpHR-expressing virus into the DMS of $\mathrm{A}_{2 \mathrm{~A}} \mathrm{R}$-Cre mice and measured electrophysiological features in the DMS and GPe (Fig. 6I). Trains of yellow light inhibited neuronal firing in the DMS iMSNs (Fig. $6 \mathrm{~J}$ ) and increased the spontaneous neuronal firing of GPe neurons (Fig. $6 K, L ; F_{(1.177,4.71)}=17.21$; Base vs $\mathrm{ON}, p=0.036$; ON vs OFF, $p=0.022)$.

\section{DMS-GPe iMSNs reduce ethanol-containing reward-seeking behavior}

Next, we examined whether the optogenetic manipulation regulates ethanol-containing reward-seeking behaviors. First, we injected the Cre-dependent ChR2-expressing virus into the DMS of $\mathrm{A}_{2 \mathrm{~A}} \mathrm{R}$-Cre mice and implanted an optic fiber into the DMS to investigate the role of DMS iMSNs in reward-seeking (Fig. 7A). Similar to the effects of pharmacological activation of $\mathrm{A}_{2 \mathrm{~A}} \mathrm{R}$, optogenetic activation (light ON) of the DMS iMSNs decreased nose-poking behavior in the water presentation (Fig. $7 B ; t=$ 2.943, $p=0.042$ ) and did not show a significant difference in nose-poke between water and 10E10S presentations (Fig. 7C; $t=$ $1.559, p=0.194)$, whereas the light OFF group showed significant difference of nose-poke (Fig. $7 C ; t=2.875, p=0.045$ ). On the other hand, blue light stimulation did not alter locomotor activity (Fig. $7 D ; F_{(1,8)}=0.004, p=0.950$ ).

Then, we injected Cre-dependent ChR2- or eNpHRexpressing virus into the DMS of $\mathrm{A}_{2 \mathrm{~A}} \mathrm{R}$-Cre mice and implanted an optic fiber into the GPe to examine the role of DMS-GPe circuits in reward-seeking (Fig. $7 \mathrm{E}, \mathrm{I}$ ). The optogenetic activation of DMS-GPe iMSNs decreased active nose-poke (Fig. 7F; $t=$ $4.209, p=0.008$ ) and time spent in the magazine (Fig. $7 H ; t=$ $3.489, p=0.018$ ) without changes in magazine entries (Fig. $7 G$; $t=1.105, p=0.320)$. However, the optogenetic inhibition of 
A

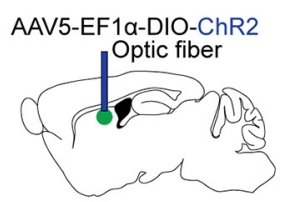

$A_{2 A}$ R-Cre mice

E

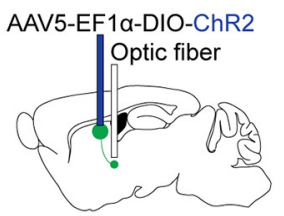

I

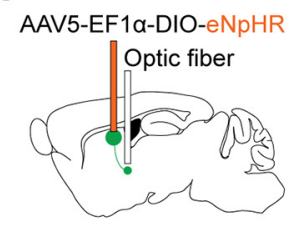

M

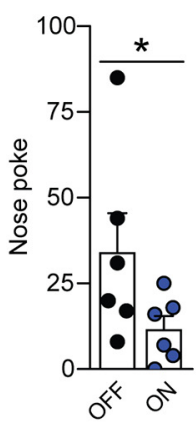

B

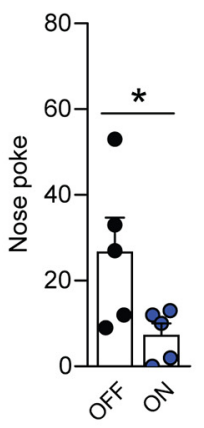

F

Active Nose Poke

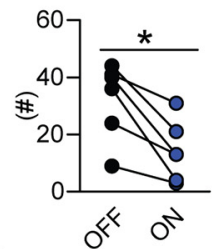

J

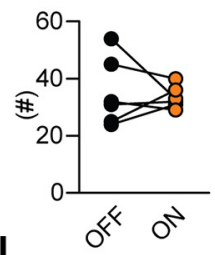

N

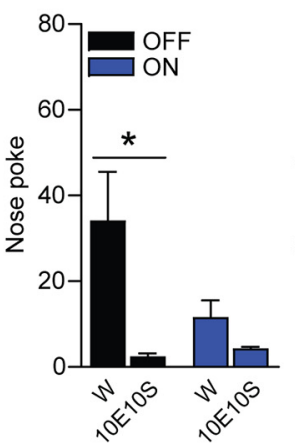

C

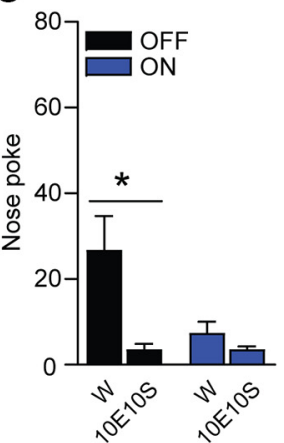

G Magazine Entry

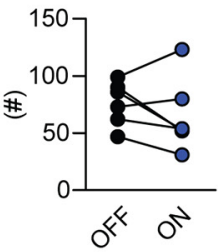

K
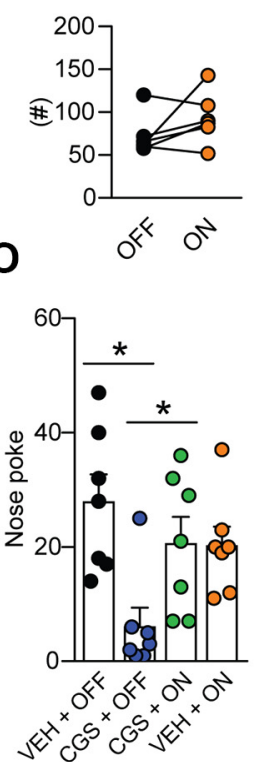

D

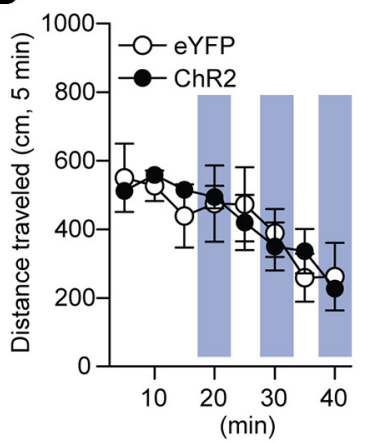

H

Time Spent in Magazine

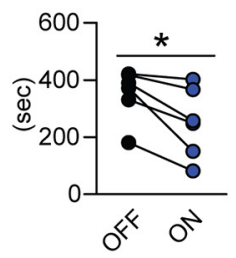

$\mathbf{L}$
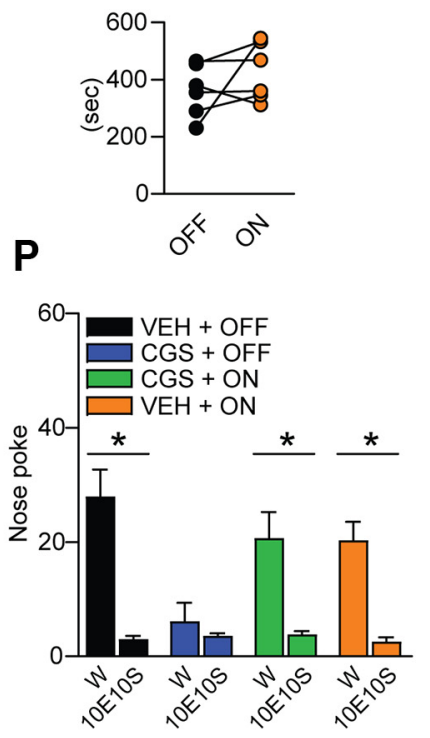

Figure 7. Optogenetic manipulations of DMS-GPe iMSNs in ethanol-containing reward-seeking behaviors. $A-D$, Injection of Cre-dependent ChR2-expressing virus and implantation of optic fiber into the DMS. $\boldsymbol{B}, \boldsymbol{M}$, Effects of blue light stimulation on nose-poke in water presentation. $\boldsymbol{C}, \boldsymbol{N}, \boldsymbol{P}$, Nose-poking changes between water (W) and 10E10S presentations. $\boldsymbol{D}$, Effects of blue light stimulation on locomotor activity. $\boldsymbol{E}-\boldsymbol{H}, \boldsymbol{M}, \boldsymbol{N}$, Injection of (re-dependent ChR2-expressing virus into the DMS and implantation of optic fiber into the GPe. Effects of light stimulation on $(\boldsymbol{F}, \boldsymbol{J})$ active nose-poke, $(\boldsymbol{G}, \boldsymbol{K})$ magazine entry, and $(\boldsymbol{H}, \boldsymbol{L})$ time spent in the magazine during CRF session. $\boldsymbol{I}-\boldsymbol{L}, \mathbf{O}, \boldsymbol{P}$, Injection of Cre-dependent eNpHR-expressing virus into the DMS and implantation of optic fiber into the GPe. $\mathbf{O}$, Effects of yellow light stimulation on nose-poke in water presentation. Data represented mean \pm SEM; $(\boldsymbol{B}-\boldsymbol{D}) n=5 /$ group; $(\boldsymbol{F}-\boldsymbol{H}, \boldsymbol{J}-\boldsymbol{N}) n=6 / \mathrm{group} ;(\boldsymbol{O}, \boldsymbol{P}) n=7 / \mathrm{group}$. ${ }^{*} p<0.05$ comparing each group. $\boldsymbol{B}, \boldsymbol{C}, \boldsymbol{F}-\boldsymbol{H}, \boldsymbol{J}-\boldsymbol{N}, \boldsymbol{P}$, Paired Student's $t$ test, (D) two-way repeated-measures ANOVA followed by Bonferroni's multiple-comparisons test, ( $\left.\mathbf{O}\right)$ one-way ANOVA followed by Tukey's multiple-comparisons test.

DMS-GPe iMSNs did not significantly change active nosepoke (Fig. $7 J ; t=0.364, p=0.731$ ), magazine entries (Fig. $7 \mathrm{~K}$; $t=1.522, p=0.188$ ), and time spent in the magazine (Fig. $7 \mathrm{~L}$; $t=1.211, p=0.280)$ in the CRF sessions. In the reward evaluation tests, optogenetic activation of DMS-GPe iMSNs dampened nose-poking behavior in the water presentation (Fig. $7 M ; t=2.749, p=0.040$ ) but did not show a significant difference of nose-poke between water and 10E10S presentations (Fig. $7 N ; t=1.895, p=0.117$ ), whereas light OFF group showed significant difference of nose-poke (Fig. $7 N ; t=2.729$, $p=0.041)$. On the other hand, optogenetic inhibition of DMS-GPe iMSNs (Fig. 7O; $F_{(3,24)}=5.989, p=0.047$ ) normal- ized the reduction of nose-poke in CGS-treated mice in the water presentation $(p=0.002)$. As expected, light OFF with CGS treatment did not show a significant difference in nosepoke between water and 10E10S presentations (Fig. $7 P$; $t=$ $0.745, p=0.485)$, but not light OFF with VEH treatment $(t=$ $5.268, p=0.002)$. Light ON with CGS treatment, however, significantly rescued nose-poking changes between the two presentations (Fig. $7 P ; t=3.951, p=0.008$ ). Similar to the effects of pharmacological inhibition of $A_{2 A} R$, light $O N$ with $\mathrm{VEH}$ treatment still showed significant nose-poking changes between the two states (Fig. $7 P ; t=4.681, p=0.003$ ). These results suggest that the manipulation of DMS-GPe iMSNs by 


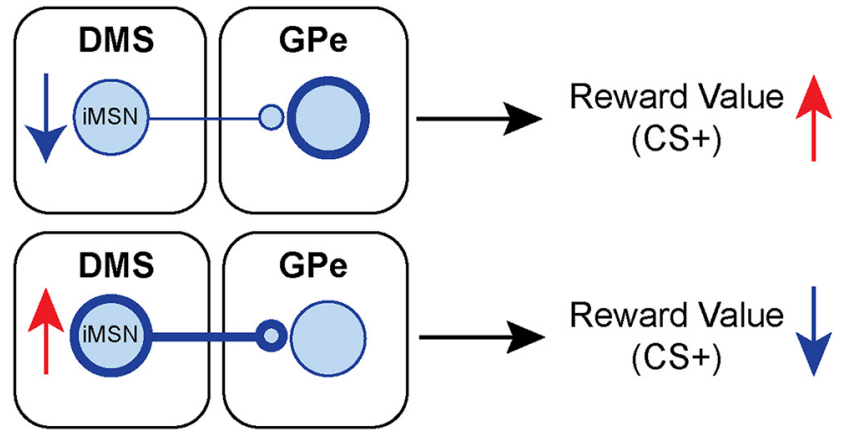

Figure 8. Schematics summarizing the results of this present study. DMS iMSNs activity reduction increases GPe neuronal activities and ethanol-containing reward-seeking behaviors with a conditioned stimulus (CS; operant chamber). However, increased DMS iMSNs activity inhibits neuronal activities in the GPe and ethanol-containing reward-seeking behaviors.

optogenetic intervention regulates ethanol-conditioning conditioned reward-seeking behaviors.

\section{Discussion}

The present study shows that DMS $\mathrm{A}_{2 \mathrm{~A}} \mathrm{R}$ and $\mathrm{A}_{2 \mathrm{~A}} \mathrm{R}$-containing iMSNs regulate the reward-seeking behavior toward the ethanolcontaining reward. The ethanol-containing conditioned reward abolishes the innate tendency of reward preference. Our finding provides a possible involvement of DMS $\mathrm{A}_{2 \mathrm{~A}} \mathrm{R}$ and iMSNs in these acquired ethanol-containing reward-seeking behaviors. Moreover, we found that intermittent ethanol exposure potentiated $\mathrm{A}_{2 \mathrm{~A}} \mathrm{R}$-dependent voluntary ethanol-containing reward-seeking behavior. Apparently, $\mathrm{A}_{2 \mathrm{~A}} \mathrm{R}$ activation impeded ethanolcontaining reward-seeking behavior, which tranquilized the DMS-GPe iMSNs. Inversely, optogenetic intervening in neuronal activity of the DMS-GPe iMSNs regulated $\mathrm{A}_{2 \mathrm{~A}} \mathrm{R}$-dependent ethanol-containing reward-seeking behavior. Therefore, DMS $\mathrm{A}_{2 \mathrm{~A}} \mathrm{R}$ and iMSNs contribute to the ethanol-containing rewardseeking behavior as illustrated in Figure 8.

In this study, we revealed that mice having food motivation preferred sucrose consumption rather than ethanol-containing outcome before the conditioning, although ethanol also has the nutrient value. This suggests that ethanol-containing outcome may not be innately preferred. Consistently, it is difficult to train mice for initiating ethanol intake in an operant chamber (Corbit et al., 2012; Noronha, 2014; Ron and Barak, 2016; Laguesse et al., 2017; Blegen et al., 2018). Our two ethanol exposure paradigms using operant conditioning with the ethanol-containing reward and intermittent ethanol exposure in the vapor chamber increased the preference of ethanol-containing reward and potentiated operant conditioning, which implies that repeated ethanol exposure may transform nonpreferred ethanol to the "reward".

Random ratio (RR) and RI schedules facilitate to the development of distinguishable reward-seeking behaviors: goal-directed behaviors and habitual seeking behaviors, respectively (Corbit et al., 2012; Gremel and Costa, 2013; Li et al., 2018). However, we used a shortened RI instrumental conditioning schedule, which also exhibits goal-directed behavior (Li et al., 2016). Thus, our finding suggests that increased ethanol-containing reward seeking could be considered goal-directed ethanol-seeking behavior as well. Further study will identify goal-directed/habitual ethanol-containing reward-seeking behaviors under different RR and RI schedules to dissect out decision-making strategies in valued and devalued states. Also, it is warranted to investigate whether MSNs regulate reward evaluation when animals show goal-directed and habitual alcohol-seeking behaviors.
We investigated the DMS indirect inhibitory pathway after the acquirement of ethanol-containing reward seeking. Rewardseeking decreases AMPA receptor activities in the DMS iMSNs (Shan et al., 2014). In addition, decreased iMSNs activities increase reward-seeking motivation and alcohol preference (Carvalho Poyraz et al., 2016; Cheng et al., 2017). Similarly, mice that exhibited seeking to ethanol-containing reward showed a decrease in DMS iMSNs activities in our study. Interestingly, we found that neither optogenetic inhibition of DMS iMSNs or pharmacological blockade of $\mathrm{A}_{2 \mathrm{~A}} \mathrm{R}$ itself altered ethanolcontaining reward-seeking behavior, whereas we previously reported that dampened adenosine dynamics and $\mathrm{A}_{2 \mathrm{~A}} \mathrm{R}$ inhibition augment seeking behavior toward the sucrose reward (Choi et al., 2004; Nam et al., 2011, 2013b). The plausible explanation of our finding is that ethanol-containing reward-seeking may decrease adenosine level and iMSNs activities through dampened $\mathrm{A}_{2 \mathrm{~A}} \mathrm{R}$ function (Butler and Prendergast, 2012; Nam et al., 2013a). Therefore, pharmacological and optogenetic inhibition of iMSNs may have no further changes in the ethanol-containing rewardseeking because of a floor effect since conditioning for rewardseeking already dampened iMSNs activities.

$\mathrm{A}_{2 \mathrm{~A}} \mathrm{R}$-mediated signaling regulates the neuronal activities in the striatum via two different mechanisms: (1) presynaptic $A_{2 A} R$ activation may increase MSNs activities through the enhancement of glutamate release from corticostriatal neurons or (2) postsynaptic $A_{2 A} R$ activation may change glutamate receptor signaling in the iMSNs. Because it has been controversial whether presynaptic $\mathrm{A}_{2 \mathrm{~A}} \mathrm{R}$ contacts to dMSNs, iMSNs, or both (Ciruela et al., 2011; Ferré et al., 2011; Lee and Chern, 2014), it may raise misinterpretation that presynaptic $\mathrm{A}_{2 \mathrm{~A}} \mathrm{R}$ activation may increase EPSCs of DMS iMSNs in our study. Moreover, the finding that mouse striatum strongly expresses dendritic $A_{2 \mathrm{~A}} \mathrm{R}$ rather than presynaptic terminal (Quiroz et al., 2009), it strengthens the role of postsynaptic $A_{2 A} R$. These provide the possibility that our electrophysiological findings show the effects of postsynaptic $\mathrm{A}_{2 \mathrm{~A}} \mathrm{R}$ activation in the DMS iMSNs on neuronal activities and excitatory postsynaptic currents.

Several other studies have suggested the combinational effects of $\mathrm{A}_{2 \mathrm{~A}} \mathrm{R}$ with other GPCRs in iMSNs. Especially, $\mathrm{D}_{2} \mathrm{R}$ is coexpressed with $A_{2 A} R$ in the iMSNs and $D_{2} R-A_{2 A} R$ heterodimer allosterically antagonize each other upon activation or inhibition through different types of G-protein (Ferré et al., 2018). Because this antagonistic $\mathrm{A}_{2 \mathrm{~A}} \mathrm{R}-\mathrm{D}_{2} \mathrm{R}$ interaction regulates reward-seeking in mice (Borroto-Escuela et al., 2018a), the precise relationship between $A_{2 A} R$ and $D_{2} R$ will elucidate how adenosine and dopamine levels regulate ethanol-seeking behaviors. Similarly, the interactions of $\mathrm{A}_{2 \mathrm{~A}} \mathrm{R}$ with other GPCRs expressed in the iMSNs have also been suggested. For example, the activation of the $A_{2 A} R$ is required for the synergy between $\mu$-opiate and cannabinoid $\mathrm{CB} 1$ receptors within the striatum, which occurs through the activation of cAMP/PKA signaling (Yao et al., 2006). Because iMSNs exhibit endocannabinoid-mediated long-term depression (Kreitzer and Malenka, 2007), it would be interesting to evaluate the role of cannabinoid receptors in the iMSNs for the $\mathrm{A}_{2 \mathrm{~A}} \mathrm{R}$-driven signaling and behavioral changes. Another iMSNsenriched GPCR, the sphingosine-1-phosphate receptor (Gpr6), which is coupled to Gs/Golf proteins, has also been implicated in goal-directed behaviors because of its well-known role in controlling instrumental conditioning via influencing the indirect pathway (Lobo et al., 2007). Recently, the putative existence of heteroreceptors with $\mathrm{A}_{2 \mathrm{~A}} \mathrm{R}$ has been proposed: $\mathrm{A}_{2 \mathrm{~A}} \mathrm{R}$-metabotropic glutamate receptor 5-NMDA receptor complexes (Borroto-Escuela et al., 2018b). Given that the development of 
ethanol-containing reward-seeking in our model was accompanied by reduced neuronal activities in the iMSNs, our findings will be helpful for delineating the antagonistic or synergistic effects of $A_{2 A} R$ and the other GPCRs in the iMSNs.

Indirect MSNs and $\mathrm{dMSN}$ distinctly code reward-seeking and reinforcement conditioning. Activation of DMS iMSNs provides transient aversion, whereas dMSNs activation induces persistent reinforcement (Kravitz et al., 2012). Furthermore, iMSNs have a higher sensitivity to outcome-dependent behavioral adjustment compared with dMSNs, even though both iMSNs and dMSNs respond similarly to reward prediction error (Shin et al., 2018). Consistently, we found that the activation of DMS-GPe iMSNs reduced ethanol-containing reward-seeking as much as the devalued state (10E10S presentation before the test) in the extinction tests. Recently developed CAMPER (cyclic adenosine monophosphate cAMP encoded reporter) strategy using different changes of cAMP level between G $\alpha$ i-coupled $A_{1} R$ and $G \alpha$ olfcoupled $\mathrm{A}_{2 \mathrm{~A}} \mathrm{R}$ may simultaneously determine the adenosine signaling-dependent dynamics of iMSNs and dMSNs in rewardseeking behaviors (Muntean et al., 2018). In the nucleus accumbens (NAc), however, it is not clear the distinction between dMSNs and iMSNs (Kupchik et al., 2015). Interestingly, both $\mathrm{D}_{1} \mathrm{R}$-expressing and $\mathrm{A}_{2 \mathrm{~A}} \mathrm{R}$-expressing MSNs are projecting to the ventral pallidum (VP; Kupchik et al., 2015; Pardo-Garcia et al., 2019). Although detailed MSN subtype-specific roles are not fully understood in reward-seeking behaviors in the NAc-VP circuit, accumbal $\mathrm{D}_{2} \mathrm{R}-\mathrm{MSN}$ are associated with aversive stimuli in reward-seeking (Creed et al., 2016) and maladaptive rewardseeking selectively depresses $\mathrm{D}_{2} \mathrm{R}$-expressing NAc-VP MSNs, but not $D_{1}$ R-expressing MSNs (Heinsbroek et al., 2017). Thus, activation of $\mathrm{A}_{2 \mathrm{~A}} \mathrm{R}$-expressing NAc MSNs may decrease reinforcing properties of drugs or drug-associated cues.

Our current study highlights the importance of the inhibitory circuit from iMSNs of the DMS-GPe in goal-directed control. The GPe, the main output brain region of iMSNs of the DMS (Ferguson et al., 2011), contains several subtypes of GABAergic neurons categorized by its localization, notable gene expression [parvalbumin, LIM homeobox 6 (Lhx6), neuronal PAS domain protein 1, forkhead box protein P2] and firing patterns (slowand fast-spiking; Mastro et al., 2014; Hernández et al., 2015; Abrahao and Lovinger, 2018). Although multiple inhibitory neuronal subtypes are innervated from the striatum (Mastro et al., 2014; Hernández et al., 2015; Yuan et al., 2017; Abrahao and Lovinger, 2018), the individual GPe cell types in response to iMSNs activities of the DMS are largely unknown. Previous studies suggest that the subdivided external segments of the GPe neurons are functionally distinguishable because of their distinct output pathways. For example, two largely different prototypical GPe cell types are classified as Lhx6-positive slowlyfiring and parvalbumin-positive fast-spiking neurons (Abrahao and Lovinger, 2018). In addition, slow firing arkypallidal neurons in the GPe are known to uniquely express FoxP2 (Abrahao and Lovinger, 2018). Evidently, although overlapping, each subpopular GPe GABAergic neurons form a distinct circuit with different brain regions. For example, although the major output pathways of the GPe neurons are the subthalamic nucleus and internal globus pallidus, the Lhx6- and parvalbumin-positive GPe neurons distinctly project to the substantia nigra and the parafascicular nucleus of the thalamus, respectively (Mastro et al., 2014). Further dissection of the DMS/DLS-GPe circuits is warranted to comprehensively understand neural connections and how the two main dorsal striatum subregions are responsible for the ethanol-seeking behaviors.
In summary, our findings uncover the roles of DMS $\mathrm{A}_{2 \mathrm{~A}} \mathrm{R}$ and DMS-GPe indirect pathway in ethanol-containing rewardseeking behavior. Importantly, we provide the possible mechanism that the DMS indirect inhibitory circuits and $\mathrm{A}_{2 \mathrm{~A}} \mathrm{R}$ signaling regulate ethanol-containing reward-seeking and a potential therapeutic target for restoring decision-making in AUD.

\section{References}

Abrahao KP, Lovinger DM (2018) Classification of GABAergic neuron subtypes from the globus pallidus using wild-type and transgenic mice. J Physiol 596:4219-4235.

Aoun EG, Jimenez VA, Vendruscolo LF, Walter NAR, Barbier E, Ferrulli A, Haass-Koffler CL, Darakjian P, Lee MR, Addolorato G, Heilig M, Hitzemann R, Koob GF, Grant KA, Leggio L (2018) A relationship between the aldosterone-mineralocorticoid receptor pathway and alcohol drinking: preliminary translational findings across rats, monkeys and humans. Mol Psychiatry 23:1466-1473.

Ayers-Ringler JR, Oliveros A, Qiu Y, Lindberg DM, Hinton DJ, Moore RM, Dasari S, Choi DS (2016) Label-free proteomic analysis of protein changes in the striatum during chronic ethanol use and early withdrawal. Front Behav Neurosci 10:46.

Blegen MB, da Silva D, Bock R, Morisot N, Ron D, Alvarez VA (2018) Alcohol operant self-administration: investigating how alcohol-seeking behaviors predict drinking in mice using two operant approaches. Alcohol 67:23-36.

Borroto-Escuela DO, Wydra K, Filip M, Fuxe K (2018a) A2AR-D2R heteroreceptor complexes in cocaine reward and addiction. Trends Pharmacol Sci 39:1008-1020.

Borroto-Escuela DO, Hinz S, Navarro G, Franco R, Müller CE, Fuxe K (2018b) Understanding the role of adenosine A2AR heteroreceptor complexes in neurodegeneration and neuroinflammation. Front Neurosci 12: 43.

Butler TR, Prendergast MA (2012) Neuroadaptations in adenosine receptor signaling following long-term ethanol exposure and withdrawal. Alcohol Clin Exp Res 36:4-13.

Calabresi P, Centonze D, Pisani A, Sancesario G, Gubellini P, Marfia GA, Bernardi G (1998) Striatal spiny neurons and cholinergic interneurons express differential ionotropic glutamatergic responses and vulnerability: implications for ischemia and Huntington's disease. Ann Neurol 43:586597.

Carvalho Poyraz F, Holzner E, Bailey MR, Meszaros J, Kenney L, Kheirbek MA, Balsam PD, Kellendonk C (2016) Decreasing striatopallidal pathway function enhances motivation by energizing the initiation of goaldirected action. J Neurosci 36:5988-6001.

Cheffer A, Castillo ARG, Corrêa-Velloso J, Gonçalves MCB, Naaldijk Y, Nascimento IC, Burnstock G, Ulrich H (2018) Purinergic system in psychiatric diseases. Mol Psychiatry 23:94-106.

Cheng Y, Huang CCY, Ma T, Wei X, Wang X, Lu J, Wang J (2017) Distinct synaptic strengthening of the striatal direct and indirect pathways drives alcohol consumption. Biol Psychiatry 81:918-929.

Choi DS, Cascini MG, Mailliard W, Young H, Paredes P, McMahon T, Diamond I, Bonci A, Messing RO (2004) The type 1 equilibrative nucleoside transporter regulates ethanol intoxication and preference. Nat Neurosci 7:855-861.

Ciruela F, Gómez-Soler M, Guidolin D, Borroto-Escuela DO, Agnati LF, Fuxe K, Fernández-Dueñas V (2011) Adenosine receptor containing oligomers: their role in the control of dopamine and glutamate neurotransmission in the brain. Biochim Biophys Acta 1808:1245-1255.

Corbit LH, Nie H, Janak PH (2012) Habitual alcohol seeking: time course and the contribution of subregions of the dorsal striatum. Biol Psychiatry 72:389-395.

Creed M, Ntamati NR, Chandra R, Lobo MK, Lüscher C (2016) Convergence of reinforcing and anhedonic cocaine effects in the ventral pallidum. Neuron 92:214-226.

Escande MV, Taravini IR, Zold CL, Belforte JE, Murer MG (2016) Loss of homeostasis in the direct pathway in a mouse model of asymptomatic Parkinson's disease. J Neurosci 36:5686-5698.

Farrell MS, Pei Y, Wan Y, Yadav PN, Daigle TL, Urban DJ, Lee HM, Sciaky N, Simmons A, Nonneman RJ, Huang XP, Hufeisen SJ, Guettier JM, Moy SS, Wess J, Caron MG, Calakos N, Roth BL (2013) A G $\alpha_{s}$ DREADD mouse for selective modulation of cAMP production in striatopallidal neurons. Neuropsychopharmacology 38:854-862. 
Ferguson SM, Eskenazi D, Ishikawa M, Wanat MJ, Phillips PE, Dong Y, Roth BL, Neumaier JF (2011) Transient neuronal inhibition reveals opposing roles of indirect and direct pathways in sensitization. Nat Neurosci 14:22-24.

Ferré S, Bonaventura J, Zhu W, Hatcher-Solis C, Taura J, Quiroz C, Cai NS, Moreno E, Casadó-Anguera V, Kravitz AV, Thompson KR, Tomasi DG, Navarro G, Cordomí A, Pardo L, Lluís C, Dessauer CW, Volkow ND, Casadó V, Ciruela F, et al. (2018) Essential control of the function of the striatopallidal neuron by pre-coupled complexes of adenosine A2Adopamine D2 receptor heterotetramers and adenylyl cyclase. Front Pharmacol 9:243.

Ferré S, Fredholm BB, Morelli M, Popoli P, Fuxe K (1997) Adenosinedopamine receptor-receptor interactions as an integrative mechanism in the basal ganglia. Trends Neurosci 20:482-487.

Ferré S, Quiroz C, Orru M, Guitart X, Navarro G, Cortés A, Casadó V, Canela EI, Lluis C, Franco R (2011) Adenosine A(2A) receptors and A(2A) receptor heteromers as key players in striatal function. Front Neuroanat 5:36.

Gęsiarz F, Crockett MJ (2015) Goal-directed, habitual and Pavlovian prosocial behavior. Front Behav Neurosci 9:135.

Gremel CM, Costa RM (2013) Orbitofrontal and striatal circuits dynamically encode the shift between goal-directed and habitual actions. Nat Commun 4:2264.

Guitart X, Bonaventura J, Rea W, Orrú M, Cellai L, Dettori I, Pedata F, Brugarolas M, Cortés A, Casadó V, Chang CP, Narayanan M, Chern Y, Ferré S (2016) Equilibrative nucleoside transporter ENT1 as a biomarker of Huntington disease. Neurobiol Dis 96:47-53.

Heinsbroek JA, Neuhofer DN, Griffin WC 3rd, Siegel GS, Bobadilla AC, Kupchik YM, Kalivas PW (2017) Loss of plasticity in the D2-accumbens pallidal pathway promotes cocaine seeking. J Neurosci 37:757-767.

Hernández VM, Hegeman DJ, Cui Q, Kelver DA, Fiske MP, Glajch KE, Pitt JE, Huang TY, Justice NJ, Chan CS (2015) Parvalbumin + neurons and Npas1+ neurons are distinct neuron classes in the mouse external globus pallidus. J Neurosci 35:11830-11847.

Jahanshahi M, Obeso I, Rothwell JC, Obeso JA (2015) A fronto-striatosubthalamic-pallidal network for goal-directed and habitual inhibition. Nat Rev Neurosci 16:719-732.

Kravitz AV, Tye LD, Kreitzer AC (2012) Distinct roles for direct and indirect pathway striatal neurons in reinforcement. Nat Neurosci 15:816-818.

Kreitzer AC, Malenka RC (2007) Endocannabinoid-mediated rescue of striatal LTD and motor deficits in Parkinson's disease models. Nature 445:643-647.

Kupchik YM, Brown RM, Heinsbroek JA, Lobo MK, Schwartz DJ, Kalivas PW (2015) Coding the direct/indirect pathways by D1 and D2 receptors is not valid for accumbens projections. Nat Neurosci 18:1230-1232.

Laguesse S, Morisot N, Shin JH, Liu F, Adrover MF, Sakhai SA, Lopez MF, Phamluong K, Griffin WC 3rd, Becker HC, Bender KJ, Alvarez VA, Ron D (2017) Prosapip1-dependent synaptic adaptations in the nucleus accumbens drive alcohol intake, seeking, and reward. Neuron 96:145-159.e8.

Lebon G, Warne T, Edwards PC, Bennett K, Langmead CJ, Leslie AG, Tate CG (2011) Agonist-bound adenosine A2A receptor structures reveal common features of GPCR activation. Nature 474:521-525.

Lee CF, Chern Y (2014) Adenosine receptors and Huntington's disease. Int Rev Neurobiol 119:195-232.

Li Y, He Y, Chen M, Pu Z, Chen L, Li P, Li B, Li H, Huang ZL, Li Z, Chen JF (2016) Optogenetic activation of adenosine A2A receptor signaling in the dorsomedial striatopallidal neurons suppresses goal-directed behavior. Neuropsychopharmacology 41:1003-1013.

Li Y, Pan X, He Y, Ruan Y, Huang L, Zhou Y, Hou Z, He C, Wang Z, Zhang X, Chen JF (2018) Pharmacological blockade of adenosine A2A but not A1 receptors enhances goal-directed valuation in satiety-based instrumental behavior. Front Pharmacol 9:393.

Lobo MK, Cui Y, Ostlund SB, Balleine BW, Yang XW (2007) Genetic control of instrumental conditioning by striatopallidal neuron-specific S1P receptor Gpr6. Nat Neurosci 10:1395-1397.

Lovinger DM, Alvarez VA (2017) Alcohol and basal ganglia circuitry: animal models. Neuropharmacology 122:46-55.

Mastro KJ, Bouchard RS, Holt HA, Gittis AH (2014) Transgenic mouse lines subdivide external segment of the globus pallidus (GPe) neurons and reveal distinct GPe output pathways. J Neurosci 34:2087-2099.
Muntean BS, Zucca S, MacMullen CM, Dao MT, Johnston C, Iwamoto H, Blakely RD, Davis RL, Martemyanov KA (2018) Interrogating the spatiotemporal landscape of neuromodulatory GPCR signaling by real-time imaging of cAMP in intact neurons and circuits. Cell Rep 24:1081-1084.

Nam HW, Lee MR, Zhu Y, Wu J, Hinton DJ, Choi S, Kim T, Hammack N, Yin JC, Choi DS (2011) Type 1 equilibrative nucleoside transporter regulates ethanol drinking through accumbal $N$-methyl-D-aspartate receptor signaling. Biol Psychiatry 69:1043-1051.

Nam HW, Bruner RC, Choi DS (2013a) Adenosine signaling in striatal circuits and alcohol use disorders. Mol Cells 36:195-202.

Nam HW, Hinton DJ, Kang NY, Kim T, Lee MR, Oliveros A, Adams C, Ruby CL, Choi DS (2013b) Adenosine transporter ENT1 regulates the acquisition of goal-directed behavior and ethanol drinking through A2A receptor in the dorsomedial striatum. J Neurosci 33:4329-4338.

Noronha A (2014) Neurobiology of alcohol dependence. Amsterdam; Boston: Elsevier/Academic.

Oude Ophuis RJ, Boender AJ, van Rozen AJ, Adan RA (2014) Cannabinoid, melanocortin and opioid receptor expression on DRD1 and DRD2 subpopulations in rat striatum. Front Neuroanat 8:14.

Pardo-Garcia TR, Garcia-Keller C, Penaloza T, Richie CT, Pickel J, Hope BT, Harvey BK, Kalivas PW, Heinsbroek JA (2019) Ventral pallidum is the primary target for accumbens D1 projections driving cocaine seeking. J Neurosci 39:2041-2051.

Paxinos G, Franklin KBJ (2001) The Mouse Brain in Stereotaxic Coordinates, Ed 2. San Diego:Academic Press.

Quiroz C, Luján R, Uchigashima M, Simoes AP, Lerner TN, Borycz J, Kachroo A, Canas PM, Orru M, Schwarzschild MA, Rosin DL, Kreitzer AC, Cunha RA, Watanabe M, Ferré S (2009) Key modulatory role of presynaptic adenosine $\mathrm{A} 2 \mathrm{~A}$ receptors in cortical neurotransmission to the striatal direct pathway. Scientific World Journal 9:1321-1344.

Renteria R, Baltz ET, Gremel CM (2018) Chronic alcohol exposure disrupts top-down control over basal ganglia action selection to produce habits. Nat Commun 9:211.

Ron D, Barak S (2016) Molecular mechanisms underlying alcohol-drinking behaviours. Nat Rev Neurosci 17:576-591.

Savola O, Niemelä O, Hillbom M (2004) Blood alcohol is the best indicator of hazardous alcohol drinking in young adults and working-age patients with trauma. Alcohol Alcohol 39:340-345.

Shan Q, Ge M, Christie MJ, Balleine BW (2014) The acquisition of goaldirected actions generates opposing plasticity in direct and indirect pathways in dorsomedial striatum. J Neurosci 34:9196-9201.

Shin JH, Kim D, Jung MW (2018) Differential coding of reward and movement information in the dorsomedial striatal direct and indirect pathways. Nat Commun 9:404.

Tozzi A, de Iure A, Di Filippo M, Tantucci M, Costa C, Borsini F, Ghiglieri V, Giampà C, Fusco FR, Picconi B, Calabresi P (2011) The distinct role of medium spiny neurons and cholinergic interneurons in the $\mathrm{D}_{2} / \mathrm{A}_{2 \mathrm{~A}}$ receptor interaction in the striatum: implications for Parkinson's disease. J Neurosci 31:1850-1862.

Viana da Silva S, Haberl MG, Zhang P, Bethge P, Lemos C, Gonçalves N, Gorlewicz A, Malezieux M, Gonçalves FQ, Grosjean N, Blanchet C, Frick A, Nägerl UV, Cunha RA, Mulle C (2016) Early synaptic deficits in the APP/PS1 mouse model of Alzheimer's disease involve neuronal adenosine $A_{2 A}$ receptors. Nat Commun 7:11915.

Wang J, Cheng Y, Wang X, Roltsch Hellard E, Ma T, Gil H, Ben Hamida S, Ron D (2015) Alcohol elicits functional and structural plasticity selectively in dopamine D1 receptor-expressing neurons of the dorsomedial striatum. J Neurosci 35:11634-11643.

Yao L, McFarland K, Fan P, Jiang Z, Ueda T, Diamond I (2006) Adenosine A2a blockade prevents synergy between $\mu$-opiate and cannabinoid CB1 receptors and eliminates heroin-seeking behavior in addicted rats. Proc Natl Acad Sci U S A 103:7877-7882.

Yin HH, Knowlton BJ (2006) The role of the basal ganglia in habit formation. Nat Rev Neurosci 7:464-476.

Yuan XS, Wang L, Dong H, Qu WM, Yang SR, Cherasse Y, Lazarus M, Schiffmann SN, d'Exaerde AK, Li RX, Huang ZL (2017) Striatal adenosine A2A receptor neurons control active-period sleep via parvalbumin neurons in external globus pallidus. eLife 6:e29055. 